REVISION DE TEMA

\title{
Fiebre amarilla en Africa: su impacto en salud pública y perspectivas para su control en el siglo XXI
}

\author{
Oyewale Tomori*
}

Durante las últimos dos décadas, la fiebre amarilla ha vuelto a emerger con fuerza hasta constituirse en un grave problema de salud pública en Africa, trayendo indecibles sufrimientos a mucha de su población y convirtiéndose en un obstáculo más para su desarrollo social y económico. A pesar de los destacados logros alcanzados en el conocimiento de la epidemiología de esta enfermedad y de la disponibilidad de una vacuna segura y eficaz, la fiebre amarilla continúa siendo un serio problema de salud pública tanto en Africa como en América en donde anualmente afecta a 200.000 personas, aproximadamente, y causa alrededor de 30.000 muertes. Africa contribuye con más del $90 \%$ de la morbilidad y mortalidad por fiebre amarilla en el planeta. Además de la severidad de la morbilidad y la mortalidad, que muestran un acusado subregistro, los sucesivos brotes y las medidas de control han traumatizado la prestación de los servicios de salud disponibles, sobrecargando los ya exiguos recursos internos, abusando de las donaciones y llevando a un lamentable desperdicio de vacunas. Las epidemias recientes en Africa han afectado predominantemente a los niños menores de 15 años.

La fiebre amarilla es una enfermedad de fácil control, lo cual puede ilustrarse con dos situaciones ocurridas en Africa. Entre 1939 y 1952, la enfermedad virtualmente desapareció en varias zonas del continente en las que se adelantaron programas de vacunación masiva de manera regular. Más recientemente, después de la epidemia de 1978-1979 en Gambia, se llevó a cabo una campaña masiva de vacunación contra la fiebre amarilla, logrando un cubrimiento de $97 \%$ de la población mayor de seis meses de edad, a partir de la cual la vacuna se incorporó permanentemente al programa de inmunización. Desde entonces, Gambia ha mantenido cubrimientos de más del $80 \%$, sin notificación de nuevos casos, a pesar de tener frontera con Senegal que padeció brotes en 1995 y 1996.

La reemergencia de la enfermedad en Africa y el fracaso en su control es el resultado de la combinación de varios factores, que incluyen: 1) el colapso de los servicios de atención en salud; 2) la falta de comprensión sobre el verdadero impacto de la fiebre amarilla en el desarrollo social y económico de las comunidades afectadas; 3) la falta de compromiso político con el control de la enfermedad de parte de los gobiernos de los países endémicos; 4) una vigilancia de la enfermedad deficiente o inadecuada; 5) medidas inadecuadas de control de la enfermedad, y 6) niveles de pobreza prevenibles, aunados a una incorrecta selección de prioridades en la asignación de presupuestos.

La fiebre amarilla puede controlarse en Africa en el lapso de los próximos diez años si: 1) los gobiernos africanos se ponen a la cabeza de las campañas de control con un compromiso indeclinable; 2) los gobiernos respaldan este compromiso a través de la asignación de presupuestos adecuados para las actividades de control de la enfermedad; 3) las organizaciones internacionales, como OMS, Unicef, Gavi, etc., facilitan apoyo y liderazgo técnico a los países en riesgo.

En un periodo de diez años, a través de campañas masivas de vacunación programadas por fases e integradas a programas regulares de vacunación exitosos, Africa puede lograr el control de la enfermedad. Por tanto, para que la fiebre amarilla deje de ser un problema de salud pública, Africa debe mantener un cubrimiento anual mínimo de vacunación contra la enfermedad

${ }^{\star}$ Autor invitado para artículo de revisión de tema 
del $80 \%$ en niños menores de un año y sostener un sistema de vigilancia confiable combinado con un programa de control y de respuesta a la enfermedad.

Esto se puede lograr con un gasto de menos de US\$1,00 por persona al año, lo cual es muy razonable siempre y cuando se reordenen las prioridades presupuestales.

Palabras clave: fiebre amarilla, epidemiología, prevención y control, historia, Africa, América

\section{Revisión histórica}

La fiebre amarilla es una enfermedad que nos acompaña desde tiempos remotos y que ha recibido tantos nombres como países la han padecido. Según Augustin (1909), "ninguna enfermedad ha tenido tantos sinónimos como la fiebre amarilla" (1). Desde 1494, cuando se la designó con el nombre de contagio, y hasta 1907 tuvo 152 sinónimos, incluidos pestilencia americana, mal de Barbados, continua pútrida, icteroides caroliniensis, Juan Amarillo, etc. Sin embargo, el término fiebre amarilla por el que hoy se le conoce, fue utilizado primero por Griffin Hughes en 1750 en su Historia natural de Barbados (1750) (2). En tanto que su origen sigue siendo objeto de gran controversia, se acepta de manera general que la enfermedad se originó ya sea en Africa o en América, en donde es endémica (figura 1) (3).

Las primeras epidemias de la enfermedad ocurrieron en Barbados, Cuba, Guadalupe y México entre 1647 y 1649. Durante los siguientes dos siglos, la América tropical y subtropical continuó padeciendo recurrentemente grandes epidemias urbanas de fiebre amarilla que "diezmaban poblaciones, paralizaban la industria y el comercio y mantenían a los pueblos de la región en permanente estado de temor a Juan Amarillo" (2). La enfermedad entró a los puertos norteamericanos en los barcos comerciales, llegando a Nueva York (1668), Boston (1691) y Charleston, Carolina del Norte (1699). Aún en 1905, hubo 5.000 casos y 1.000 muertes en ciudades porteñas del sur de los Estados Unidos. Durante el siglo XVIII, la enfermedad se extendió a Italia, Francia y España y en 1800, más de

\footnotetext{
Correspondencia:

Oyewale Tomori, WHO Office, P.O. Box BE 773, Belvedere, Harare, Zimbabwe
}

Recibido: 19/04/02; aceptado: 26/04/02
60.000 muertes se atribuyeron a la epidemia española de la enfermedad (2).

Con frecuencia, la fiebre amarilla ha cambiado el curso de la historia. Este fue el caso del ataque británico a Cartagena en 1741 encaminado a destruir el poderío español en el Caribe. En formación de batalla contra las fuerzas españolas compuestas por seis barcos y 2.700 hombres, la armada británica desplegó su abrumadora fuerza con 124 navíos y 23.000 hombres (4). La aliada silenciosa de los españoles fue la fiebre amarilla. Poco después de su arribo, los soldados ingleses 'vírgenes' cayeron víctimas de las balas de los defensores españoles y de la disentería y la fiebre amarilla; muchos comenzaron a sentirse afiebrados y con dolor de cabeza; las náuseas, el vómito y los dolores musculares de espalda hicieron presa de ellos. En muchos, la enfermedad avanzó hasta la ictericia, con ojos inyectados y hemorragias. Al final, los británicos no sólo perdieron la batalla sino también a 8.400 soldados, alrededor del $37 \%$ de su ejército, y cerca del $50 \%$ de sus hombres convalecientes de los estragos de la enfermedad. En el bando contrario, los españoles, muchos de los cuales estaban familiarizados con la fiebre amarilla, perdieron sólo 600 hombres, un $22 \%$ de sus efectivos. De no haber sido por este brote de la enfermedad en 1741 en Cartagena, Colombia tal vez hubiera quedado bajo el mandato británico y su lengua hubiera sido el inglés y no el español.

Probablemente hubo epidemias de fiebre amarilla en Africa mucho antes de la documentada en 1778 que, según los recuentos, diezmó las tropas británicas estacionadas en Saint Louis, Senegal $(1,3)$. Sin embargo, no fue sino hasta 1925 que se inició una investigación seria de la enfermedad en Africa occidental. En 1848, Josiah Nott expresó por primera vez la idea de que los mosquitos debían servir de agentes para la diseminación tanto de la fiebre amarilla como de la malaria (5). No obstante, el crédito por la teoría del mosquito 


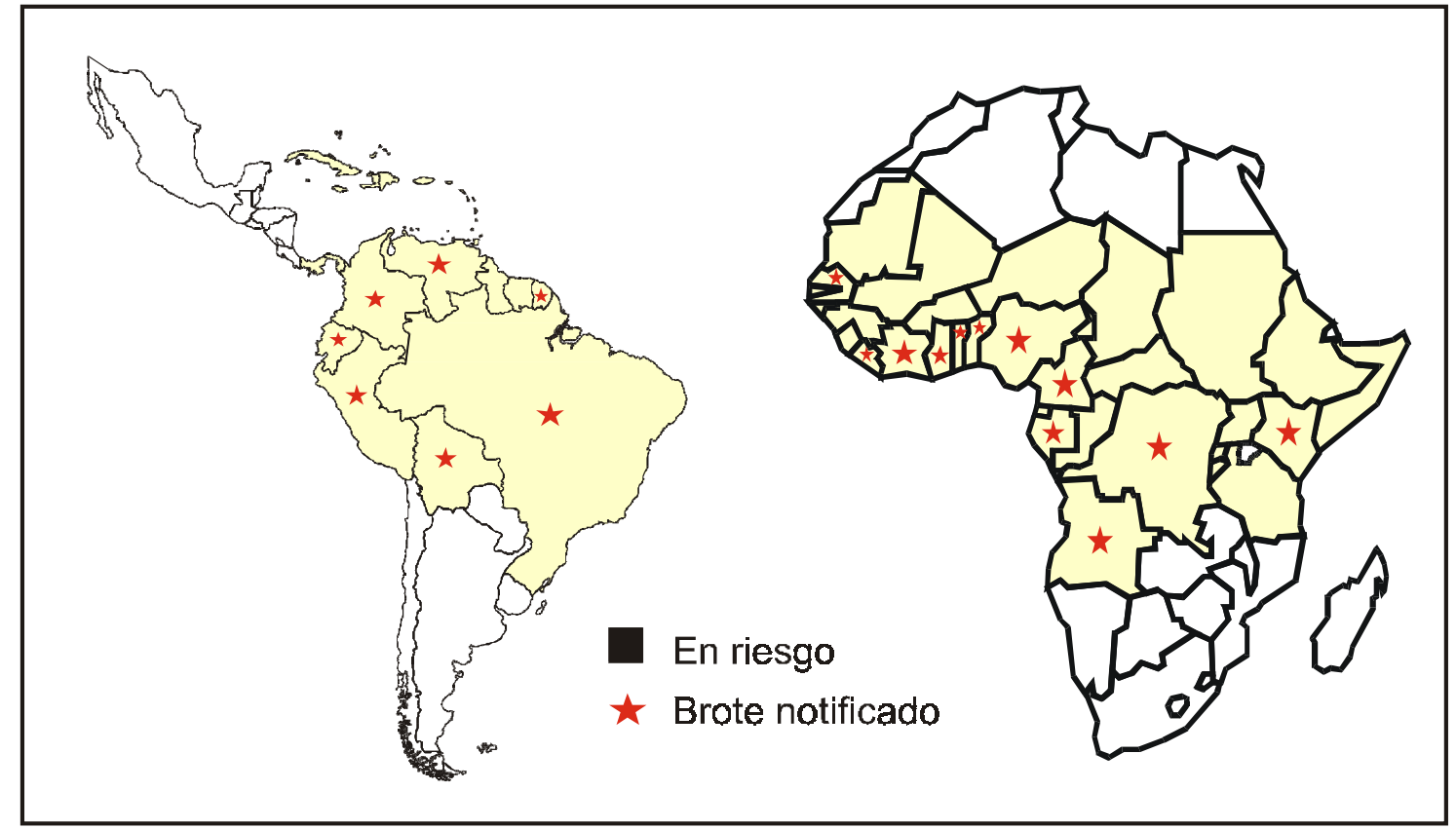

Figura 1. Países en riesgo de fiebre amarilla y que han notificado al menos un brote, 1985-1999.

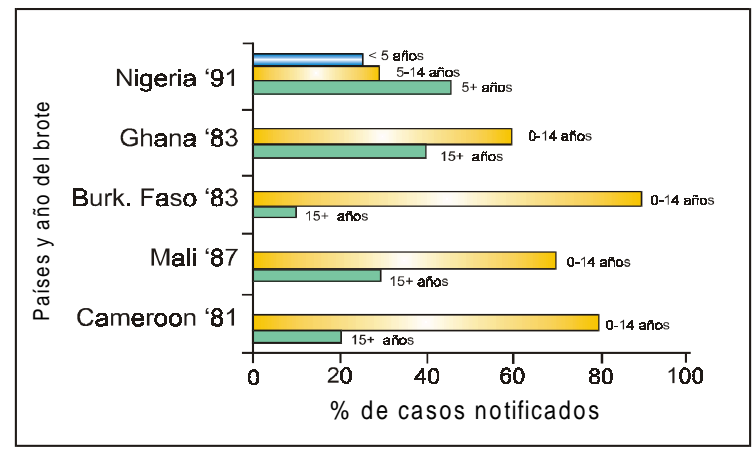

Figura 2. Distribución por edades de casos notificados de fiebre amarilla durante brotes seleccionados, 1981-1991.

como vector de la transmisión de la fiebre amarilla se le dió a Carlos Finlay de La Habana, Cuba, quien en 1881 propuso la teoría en un estudio presentado en la Academia de Ciencias, en sesión celebrada en esa ciudad $(1,2,6)$. Reed y sus colegas demostraron más tarde que la fiebre amarilla es causada por un agente filtrable y que el mosquito Aedes aegyptipodía ser el transmisor de la enfermedad. Después de la erradicación exitosa de la fiebre amarilla en La Habana y en Panamá a comienzos del siglo XX con la aplicación de medidas antivectoriales $(1,2)$, se extendió la creencia de que el mosquito $A$. aegypti era el responsable exclusivo de la transmisión de la fiebre amarilla. Sólo con la aparición de los estudios realizados por Soper y colaboradores se corrigió tan extendida opinión (8). Sus hallazgos, más tarde confirmados en otras partes del trópico $(9,10)$, llevaron a establecer la noción de que la transmisión de la fiebre amarilla selvática involucraba monos salvajes y especies silvestres de mosquitos y a tomar conciencia de que el control de la fiebre amarilla requeriría más que las medidas para combatir el mosquito. En 1927, Mahaffy y Bauer de la Comisión Rockefeller de Fiebre Amarilla (RYFC, por sus siglas en inglés), aislaron el virus de la fiebre amarilla inoculando sangre de un paciente de Ghana en monos Rhesus (2). La cepa, llamada Asibi, se atenuó con pases realizados en tejido embrionario de pollo y, posteriormente, el virus modificado (17D) se convirtió en la fuente para la vacuna contra la fiebre amarilla en humanos $(11,12)$. En otros estudios $(13,14)$, el equipo de la RYFC confirmó que: 1) el agente causal de la fiebre amarilla era un virus filtrable; 2) la infección 
se transmitía fácilmente del hombre al mono o de mono a mono inyectando sangre citratada de muestras tomadas en los primeros estadios de la enfermedad; 3) que una vez infectados, los mosquitos permanecían infectivos de por vida, la cual podía extenderse hasta tres meses o más, y 4) que la picadura de un sólo mosquito infectado era suficiente para producir una infección fatal en monos.

A pesar de estos avances históricos en el conocimiento de su epidemiología y de la existencia de una vacuna segura y eficaz, la fiebre amarilla continúa siendo un grave problema de salud pública tanto en Africa como en América, lugares en los que anualmente afecta a cerca de 200.000 personas y causa la muerte a otras 30.000 (3). Las epidemias recientes en Africa han afectado principalmente a niños menores de 15 años (figura 2) (15-17).

\section{El virus}

El virus de la fiebre amarilla pertenece al género de los Flavivirus de la familia Flaviviridae (18). Constituye el prototipo del género y la familia consta de más de 70 virus relacionados pero diferenciados, la mayoría de los cuales son transmitidos por artrópodos (19). Otros patógenos importantes de esta familia son el virus del dengue y el virus de la encefalitis japonesa. El virus de la fiebre amarilla tiene estrecha relación antigénica con los virus Banzi, Wesselsbron, Bouboui, Zika y Uganda S, todos ellos miembros de la familia Flaviviridae y nativos de Africa (19). Se han demostrado diferencias antigénicas entre cepas del virus de la fiebre amarilla y se han utilizado técnicas policlonales de absorción de anticuerpos y características de virulencia en ratones con el fin de distinguir entre las cepas de virus de la fiebre amarilla americanas y africanas y entre el $17 \mathrm{D}$ de la vacuna y los virus Asibi padre $(19,20)$. También se han usado patrones de migración electroforética y medición de los contenidos de proteína $\mathrm{E}$ para distinguir entre las cepas americanas y africanas del virus $(21,22)$. Dichos estudios identifican únicamente dos genotipos del virus en Africa y uno o posiblemente dos en Suramérica. Los dos genotipos africanos están representados por las cepas de virus de Africa occidental y la de Africa central y oriental. A través de la exploración

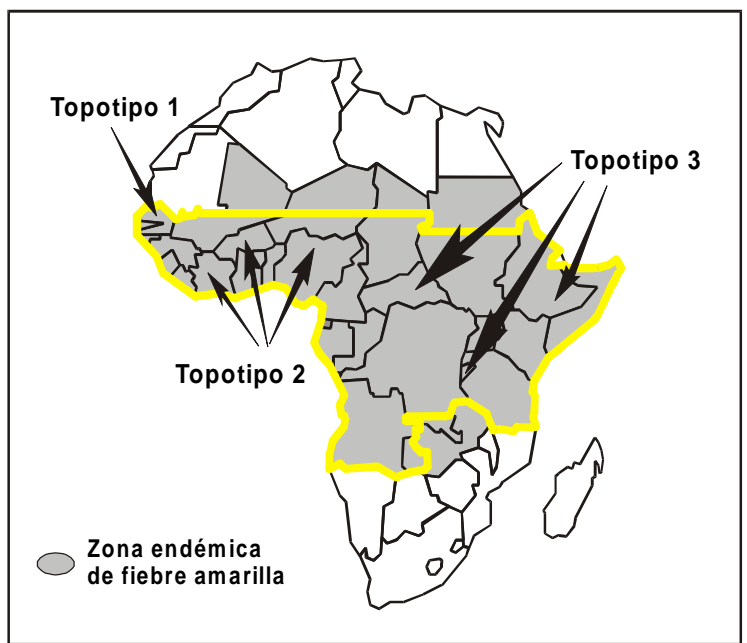

Figura 3. Distribución de topotipos de fiebre amarilla en Africa.

(mapping) de oligonucleótidos de ARN, tales genotipos se han segregado en tres diferentes topotipos de regiones no superpuestas 0 variantes (figura 3) (22). El genotipo de Africa occidental consta de dos variantes, la SenegalGambia y la Costa de Marfil-Burkina FasoNigeria, en tanto que sólo se ha detectado una variante representativa del genotipo de Africa central y oriental (22). Las variantes muestran una considerable estabilidad genética a través del tiempo, lo que indica que las epidemias surgen de fuentes locales (23). Uno de los genotipos suramericanos no se ha podido recuperar desde 1974 , lo que sugiere que el virus pudo haberse perdido del todo. Todas las demás cepas suramericanas pertenecen a un gran grupo filogenético, que, en contraste con los virus africanos, no se distribuye en topotipos geográficos discretos.

El pequeñísimo virus de la fiebre amarilla (35 a $45 \mathrm{~nm}$ ) posee un genoma de ARN monocatenario de polaridad positiva con 10.862 nucleótidos de masa molecular aproximada de $3,75 \times 10^{6}$. Codifica para tres proteínas estructurales y hasta para 12 no estructurales, las cuales se sintetizan en las células infectadas (24). El genoma está recubierto por una envoltura que contiene una sola glicoproteína con determinantes antigénicos específicos de tipo y grupo. El virus se inactiva con éter, cloroformo, deoxicolato de sodio, 
proteasas, lipasas, por calor $\left(56{ }^{\circ} \mathrm{C}\right.$ durante 30 $\mathrm{min}$ ) y con luz ultravioleta (25).

El virus se replica en una amplia variedad de cultivos celulares primarios y continuos (18), los cuales incluyen células de riñón de mono (MA104, Vero, LLC-MK2), riñón de hámster recién nacido (BHK) y líneas celulares de riñón porcino, así como monocapas primarias de pollo y fibroblastos de embrión de pato. Las cepas de las vacunas (la 17D y los virus neurotrópicos franceses) obtienen títulos más altos y producen efectos citopáticos más evidentes en estos cultivos. Con las cepas salvajes, la formación de placas es inconsistente y varía de cepa a cepa. Tanto la 17D como el virus Asibi padre crecen en cultivos celulares de origen humano, tales como las células hepáticas Chang, las de intestino embriónico de Henle, HeLa y KB. Para el aislamiento primario, los cultivos celulares de mosquito son más sensibles a las células Vero o de ratón recién nacido (18). Mientras que las células de Aedes pseudoscutellaris (AP-61) muestran efectos citopáticos de manera consistente después de la infección con virus de fiebre amarilla, las infecciones de $A$. aegypti clonado y de las células pueden demostrarse por inmunofluorescencia por subpases a ratón o a células Vero (18). La inoculación intratorácica de mosquitos Toxorhinchites o $A$. aegypti es otro método de aislamiento del virus de la fiebre amarilla. Después de 10 a 16 días de incubación, los mosquitos inoculados pueden examinarse directamente por inmunofluorescencia o por subpases a un hospedero susceptible, por ejemplo, ratones lactantes (18). El virus produce patrones de infección tanto neurotrópicos como viscerotrópicos en diversos hospederos vertebrados. Los ratones recién nacidos son altamente susceptibles a la encefalitis después de la inoculación intraperitoneal o intracerebral (18). Sin embargo, existe una variación considerable entre cepas en cuanto a su neuropatogenicidad en ratones. Los ratones adultos, así como los cobayos, son susceptibles cuando se usa la vía intracerebral. Los monos inoculados intracerebralmente con virus salvajes desarrollan encefalitis pero mueren de fiebre amarilla viscerotrópica. En el hombre y en los primates no humanos (Macacos rhesus cynomolgus), el vicerotropismo es característico de la infección con virus de la fiebre amarilla por vía periférica (18). Como se ha informado para otros Flavivirus $(17,18)$, la síntesis viral y la madurez ocurren predominantemente en el retículo endoplásmico rugoso de la célula hospedera, en tanto que no hay claridad sobre el sitio de formación de la envoltura que rodea el virión. Las partículas virales maduras se acumulan en la cisterna de los organelos membranosos y son liberados de la célula por exocitosis o por ruptura de la membrana plasmática. La síntesis macromolecular de la célula hospedera no se ve afectada seriamente por la infección (18). El tratamiento de las células con actinomicina $D$ inhibe la síntesis de ARN en la célula hospedera pero no afecta la síntesis viral de ARN. El pico de la síntesis de ARN ocurre cuando los títulos virales en el sobrenadante alcanzan el máximo. Se observan entonces tres tipos de ARN viral: el ARN del tamaño del genoma con un coeficiente de sedimentación de 40S; el ARN ARNasa resistente, identificado como el intermediario replicativo, soluble en $2 \mathrm{~mol} / \mathrm{lde} \mathrm{HCl}$ y que sedimenta cerca de 20S, y el ARN ARNasa parcialmente resistente, el cual se presume es la forma replicativa y que sedimenta cerca de $28 \mathrm{~S}$ (18).

\section{La enfermedad}

La fiebre amarilla es una enfermedad infecciosa aguda caracterizada por la aparición repentina con dos fases de desarrollo separadas por un breve periodo de remisión (17). El espectro clínico de la fiebre amarilla varía desde el malestar leve, no específico y febril hasta la enfermedad fulminante $y$, algunas veces, fatal con rasgos patognomónicos. La enfermedad grave o clásica, que usualmente se evidencia durante las epidemias, comienza de forma abrupta después de un periodo de incubación de tres a seis días o más a partir de la picadura del mosquito infectado. La fiebre $\left(39-40{ }^{\circ} \mathrm{C}\right)$, los escalofríos, la cefalea intensa, los dolores musculares lumbosacros y generalizados, las náuseas y el vómito y la conjuntiva inyectada son los signos y síntomas asociados con la primera fase de la infección (17), síndrome que dura de tres a cinco días. En esta 
etapa la orina es de color oscuro y la albuminuria puede estar ausente. El pulso lento con relación a la fiebre (signo de Faget) también es típico de esta fase, a la cual generalmente sigue un período de remisión de entre 12 y 24 horas, marcado por la disminución de la fiebre, la desaparición del dolor de cabeza y una mejoría en la condición general del paciente. Esta fase de remisión da paso al período de intoxicación o fase hepatorrenal, en la cual la fiebre vuelve a subir, reaparecen todos los síntomas, con vómitos más frecuentes, dolor epigástrico y postración (17). Aparece, así mismo, la ictericia y la diátesis hemorrágica, otro rasgo común de esta etapa, que se manifiesta por hematemesis (vómito negro), melena, metrorragia, petequias, equimosis y secreciones difusas de las membranas mucosas. La deshidratación resulta del vómito y de la pérdida insensible de líquidos. La disfunción renal se caracteriza por un incremento súbito en la albuminuria y por disminución del volumen urinario. La taquicardia progresiva, el choque y el hipo incontrolable se consideran signos ominosos y terminales. La tasa de mortalidad en la fiebre amarilla grave es de $50 \%$ o más. La muerte usualmente ocurre entre el séptimo y el décimo día desde la aparición de la enfermedad y para quienes sobreviven, la convalecencia, marcada por la astenia aguda, puede prolongarse de una a dos semanas.

\section{Tratamiento}

En ausencia de una terapia específica, el tratamiento de los casos de fiebre amarilla es básicamenete de apoyo $(17,18)$ y puesto que la mayoría de los casos ocurre en áreas carentes de las facilidades hospitalarias básicas, los pacientes no tienen acceso a los modernos cuidados intensivos. En la fase temprana de la enfermedad, la terapia debe centrarse en el control de la fiebre y el vómito, el alivio de la cefalea y los dolores abdominales y el manejo de la deshidratación. Durante la etapa de intoxicación, la terapia más adecuada se basa en la supervisión cuidadosa del paciente para controlar la hemorragia y las manifestaciones asociadas con el daño hepatorrenal. Cuando sea necesario se deberá administrar el tratamiento para el control de la malaria y de las infecciones bacterianas secundarias $(17,18)$.

\section{Diagnóstico}

Desde el punto de vista clínico es difícil diferenciar la fiebre amarilla de otras enfermedades tropicales y a menudo es imposible cuando la condición es leve o atípica. Los síntomas clínicos asociados con las etapas tempranas de la infección son indeferenciables de los de la malaria y cuando las dos afecciones coexisten no es aconsejable descartar la fiebre amarilla aún en ausencia de ictericia o por la presencia de parásitos de malaria en las muestras de sangre. Otras enfermedades similares a la fiebre amarilla anictérica incluyen la fiebre tifoidea, las rickettsiosis, otras fiebres arbovirales y la influenza. La fiebre amarilla también debe diferenciarse de otras enfermedades que producen disfunción hepatorrenal 0 manifestaciones hemorrágicas tales como la hepatitis viral, la fiebres virales hemorrágicas (la fiebre de Lassa, las causadas por los virus de Marburg y Ebola, la fiebre hemorrágica de CrimeaCongo, la fiebre del valle de Rift), la leptospirosis, etc. $(17,18)$.

El diagnóstico por el laboratorio requiere de reactivos y técnicas especiales, así como de la pericia en la interpretación de los resultados de las pruebas. El diagnóstico específico depende de los estudios histopatológicos, del aislamiento del virus, la detección del antígeno viral o de la respuesta de anticuerpos específicos $(17,18)$. Para la histopatología, las muestras de tejido hepático se pueden obtener de casos fatales por incisión abdominal o utilizando el viscerótomo o una aguja de biopsia de largo calibre. Las muestras de tejido hepático obtenidas de un paciente que haya muerto antes del décimo o duodécimo día despues del comienzo de la infección son igualmente adecuadas para aislar el virus. Los especímenes deben dividirse en porciones separadas para el aislamiento del virus y para la fijación para histopatología.

Los especímenes para histopatología deben fijarse ya sea en solución de Boiun o en formol al 10\%. El examen de un corte en parafina de un caso típico de la enfermedad revela una degeneración eosinofílica de los hepatocitos conducente a la formación de cuerpos de Councilman, necrosis prominente de la zona media y esteatosis microvacuolar. Sin embargo, la histopatología de 
otras infecciones como la fiebre de Lassa, las enfermedades causadas por los virus Marburg y Ebola, la fiebre hemorrágica de Crimea-Congo, la hepatitis viral y la leptospirosis pueden confundirse fácilmente con la de la fiebre amarilla. El virus se aisla más fácilmente a partir de suero obtenido durante la etapa aguda en los primeros cuatro días de la infección, pero también puede recuperarse del suero hasta el décimocuarto día y, como ya se anotó, del tejido hepático de un paciente recién fallecido. Son varios los métodos disponibles para el aislamiento del virus a partir de especímenes clínicos, entre los cuales cabe mencionar la inoculación en ratones lactantes, la inoculación intratorácica de mosquitos o la inoculación de cultivos celulares. El virus aislado puede identificarse a través de varias pruebas serológicas. Se dispone de una prueba ELISA para la captura de antígenos, la cual es sensible al aislamiento en ratones lactantes y permite una detección rápida del virus en suero, sangre e hígado (18).

Para el diagnóstico serológico de la infección, se recomiendan los siguientes métodos: inhibición de la hemaglutinación (IH), fijación del complemento $(\mathrm{FC})$, neutralización $(\mathrm{N})$, hemólisis radial simple, ELISA, IF y RIA (17). Los anticuerpos para IH, IF y $\mathrm{N}$ aparecen durante la primera semana a partir de la irrupción de la infección, en tanto que los anticuerpos para FC aparecen más tarde. La prueba de neutralización de reducción de placas ha venido a reemplazar la prueba de neutralización en ratones susceptibles, la cual es mucho menos sensible. Los sueros combinados, obtenidos durante las fases aguda y de convalescencia, se requieren para confirmar el diagnóstico al evidenciar un incremento significativo (usualmente hasta de cuatro veces) en los títulos de anticuerpos. La determinación de los anticuerpos IgM ya sea por IF indirecta o ELISA puede indicar infección reciente. La duración de los anticuerpos IgM parece ser bastante variable. Se puede realizar un diagnóstico presuntivo de infección reciente por fiebre amarilla cuando los anticuerpos IgM se detectan por medio de ELISA o IF o cuando hay títulos altos de anticuerpos FC específicos en una muestra única tomada durante el periodo de convalescencia. Aunque los anticuerpos IgM muestran relativa especificidad, las exposiciones previas a otros Flavivirus ocasionalmente puede complicar la interpretación de los resultados. En personas que no hayan estado expuestas anteriormente a Flavivirus, la vacuna 17D contra la fiebre amarilla induce a la producción de anticuerpos neutralizantes, la seroconversión y títulos bajos de anticuerpos $\mathrm{IH}(1: 19-1: 40)$, pero no detectables por IF o FC. Sin embargo, las personas con anticuerpos de Flavivirus preexistentes responden a la vacuna 17D con incrementos agudos de fiebre amarilla y anticuerpos IH y FC heterólogos $(17,18)$.

\section{Ecología de la fiebre amarilla}

La transmisión del virus ocurre entre humanos, mosquitos y monos $(2,18)$. El mosquito vector, que puede pertenecer a una de varias especies, se infecta al alimentarse de un hospedero virémico (hombre o mono) y, luego, trasmite el virus a otro hombre o mono susceptible. A pesar de que los humanos y los monos se han considerado como reservorios de fiebre amarilla, el verdadero reservorio es la especie de mosquito susceptible, que no sólo permanece infectada de por vida, sino que puede transmitir el virus transováricamente a una proporción de descendientes a través de los huevos infectados. De otra parte, el hombre y los monos juegan el papel de amplificadores temporales de la cantidad de virus disponible para la infección del mosquito. En el hombre, la viremia alta, necesaria para la infección del mosquito, dura desde el propio desencadenamiento de la infección hasta más o menos el cuarto día después del inicio de la infección, cuando los anticuerpos específicos comienzan a aparecer. La mayoría de las especies de monos africanos desarrollan una viremia efectiva que se prolonga durante varios días y produce anticuerpos protectores después de la viremia. A diferencia de algunas especies americanas, los monos africanos raras veces mueren por infección de fiebre amarilla. Los monos aulladores americanos (Alouatta sp.), los monos araña (Ateles sp.), los monos ardilla (Saimiri sp.) y los monos lechuza (Ateles sp.) desarrollan altos niveles de viremia y con frecuencia mueren de fiebre amarilla (17). De otra parte, los monos capuchinos (Cebus sp.) y los monos lanudos (Lagothirx sp.) desarrollan 


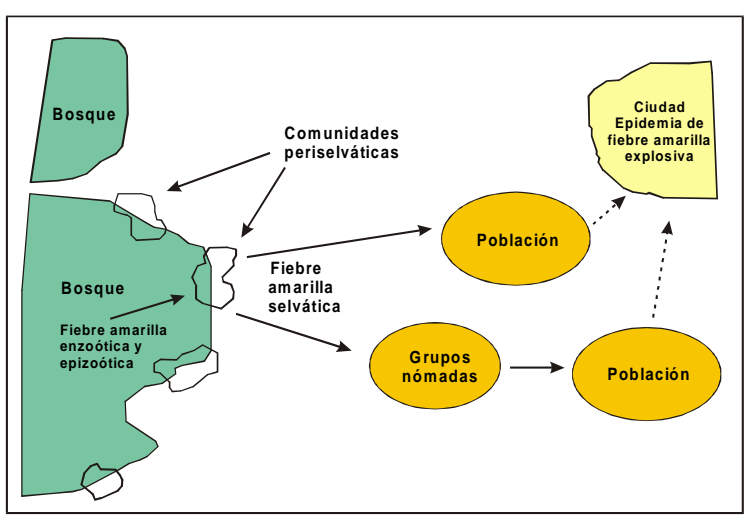

Figura 4. Ciclos de transmisión del virus de la fiebre amarilla.

infecciones subclínicas de fiebre amarilla con viremia. El papel de otros vertebrados no humanos en la transmisión de la fiebre amarilla, tales como el galago africano de los arbustos y los desdentados, marsupiales y roedores suramericanos, permanece indefinido y requiere de investigaciones futuras (18).

\section{Epidemiología}

En las Américas operan dos tipos de ciclos epidemiológicos: el selvático y el urbano (17). Las epidemias de fiebre amarilla urbana se transmiten de hombre a hombre por medio del mosquito $A$. aegypti, en tanto que el tipo selvático se transmite por la picadura de un Haemagogus infectado con fiebre amarilla o por otros mosquitos de zonas boscosas. La actividad del virus es baja con casos esporádicos y brotes focalizados.

En Africa se reconcen tres patrones epidemiológicos diferentes de transmisión del virus de la fiebre amarilla, que conducen al mismo cuadro clínico (figura 4) (17). Son éstos, el ciclo selvático, el ciclo urbano mediado por $A$. aegypti y un ciclo intermedio que enlaza los ciclos selvático y urbano. La transmisión se determina por la complejidad de las zonas de vegetación, los patrones de precipitación, la abundancia y distribución de hospederos vertebrados y los mosquitos vectores. En el bosque húmedo ecuatorial que se extiende desde Guinea en el occidente hasta Uganda en el oriente y al sur hasta la parte norte de Angola, se da una transmisión anual de la fiebre amarilla entre los monos y los mosquitos Aedes africanus de manera análoga a la de la fiebre amarilla selvática en Suramérica. La transmisión se produce predominantemente de mono a mono, con infección esporádica de humanos $(17,23)$. Las sabanas húmedas y semihúmedas se desprenden del bosque húmedo africano; sin embargo, durante la temporada de lluvias, en la cual hay altas densidades de población de hospederos y vectores selváticos (Aedes furcifer, Aedes luteocephalus, Aedes vittatus), estas áreas de bosque mosaico de sabana y de sabana húmeda (Guinea) experimentan tasas frecuentes y a menudo altas de transmisión de fiebre amarilla (17). Epizootias periódicas de fiebre amarilla ocurren en las poblaciones de monos con transmisión interhumana. La supervivencia del virus y la continuidad de la epizootia se aseguran a través de la transmisión vertical en los mosquitos. Con la ocurrencia de las mayores epidemias de fiebre amarilla en esta zona de vegetación, ésta se constituye en el área de mayor riesgo para la transmisión, conocida también como la zona intermedia de transmisión (17). La zona de sabanas secas se caracteriza por baja precipitación y una breve temporada de lluvias, por lo cual, las poblaciones de vectores selváticos son muy bajas o activas sólo por un corto periodo como para mantener la epizootia. No obstante, la infección por fiebre amarilla puede introducirse en la zona de sabanas secas y mantenerse en un ciclo de transmisión interhumana a través de vectores domésticos ( $A$. aegypti), después de extenderse a partir de una epizootia de la zona intermedia o por el desplazamiento de personas hacia las villas. Las epidemias explosivas

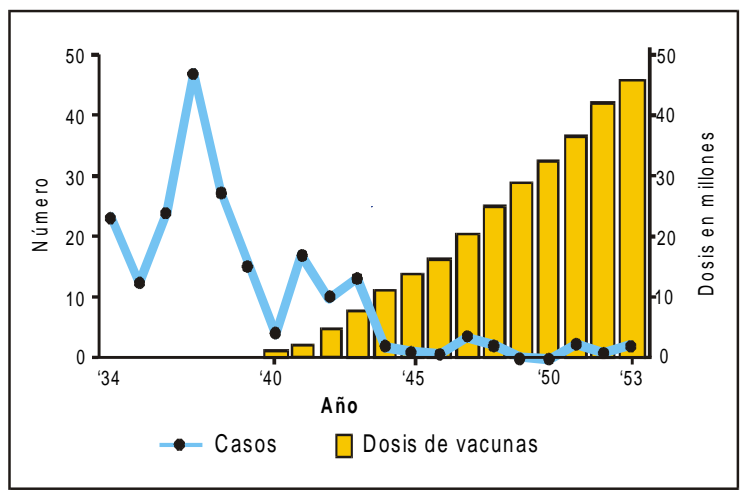

Figura 5. Control de la fiebre amarilla en Africa: el milagro de 1934-1953. 
causadas por $A$. aegyptiocurren cuando el virus es introducido en centros urbanos o en regiones de sabana muy secas donde el agua se almacena en las casas y sus alrededores y la población humana convive con $A$. aegypti doméstico (17). Bajo tales condiciones, la epidemia puede extenderse a lugares distantes y de población en población siguiendo las coordenadas del desplazamiento humano (figura 4). La extensión y la velocidad de diseminación del virus sólo se ven limitadas por la distancia que una persona o mosquito infectado pueda cubrir a través de los medios de transporte disponibles.

\section{Prevención y control}

Son dos las vacunas biológicas atenuadas utilizadas en la prevención y control de las epidemias de fiebre amarilla (26). La vacuna neurotrópica francesa (VNF) se desarrolló a partir de 1930 con cerebro disecado de ratones inoculados con la cepa neurotrópica francesa del virus de la fiebre amarilla (27). Entre 1939 y 1953, más de 80 millones de aplicaciones de la vacuna se hicieron por escarificación (figura 5), lo que condujo a la virtual desaparición de la fiebre amarilla en los países francófonos de Africa (28). Sin embargo, se presentaron graves reacciones postvacunales (18), incluidos síntomas sistémicos en cerca del $20 \%$ de los casos, signos meníngeos en 3-4\% y encefalitis postvacunal en 0,5 a $1,3 \%$ de los casos. El intento de controlar la epidemia de fiebre amarilla de 1965 en Senegal con el uso de la vacuna neurotrópica resultó en la identificación de 248 casos de encefalitis con una tasa de mostalidad del $22 \%$ (23). La vacuna neutrópica francesa fue descontinuada en 1980 (26). La otra vacuna, la 17D, es una vacuna biológica atenuada eficaz y segura preparada a partir de embriones de pollo (12). Cerca del 95\% de los vacunados desarrolla cantidades apreciables de anticuerpos dentro de los diez días posteriores a la aplicación. Para efectos de certificación internacional, la inmunización cubre diez años pero la inmunidad puede ser de por vida, pues se ha demostrado que los anticuerpos persisten durante $30 \circ 35$ años (18). Las reacciones adversas a la 17D incluyen dolor de cabeza ligero, mialgias y otros síntomas leves en 2 a $5 \%$ de las personas que la reciben. Las reacciones alérgicas, incluido el salpullido, la urticaria y el asma, ocurren muy poco (menos de uno en un millón, predominantemente en personas con antecedentes de alergia al huevo). No se han asociado anormalidades hepáticas a la vacuna y los riesgos de encefalitis asociados con ella son mínimos, siendo la 17D la única vacuna que se produce actualmente $(18,26)$. En los países endémicos se requiere la promoción de estrategias de inmunización efectiva tanto de rutina como suplementarias para su control (16). Las cuatro estrategias propuestas para la prevención y control de la fiebre amarilla son las inmunizaciones regulares, la vigilancia, incluidas la monitorización y el control de vectores, la prevención de brotes y la respuesta a brotes (29). Todos los países en riesgo requieren de un sistema de vigilancia continuo y sensible para la detección temprana de casos como prerrequisito para la respuesta rápida de contención de potenciales brotes. Son esenciales, así mismo, los laboratorios equipados para el diagnóstico diferencial debido a la dificultad para diferenciar la enfermedad de otras con síntomas similares tales como la hepatitis, la malaria, la fiebre tifoidea y otras ictericias febriles. Otras medidas preventivas incluyen la monitorización y el control de vectores (29). Los programas permanentes y coordinados de eliminación de sitios de cría (neumáticos, recipientes artificiales, etc.) de vectores domésticos ( $A$. aegypti), así como el tratamiento del agua potable con abate $\mathrm{R}$ y la aspersión perifocal con insecticidas organofosforados son pasos efectivos en la interrupción de la transmisión del virus (29).

\section{Impacto de la fiebre amarilla sobre el desarrollo a través de las edades}

La fiebre amarilla ha sido la causa de sufrimientos y calamidades indecibles entre las poblaciones de América, Europa y Africa en diferentes etapas del desarrollo de nuestras sociedades. Cientos de miles de personas se vieron afectadas por la enfermedad a través de los tiempos y de ellas decenas de miles murieron. La fiebre amarilla trajo consigo el desastre económico, constituyéndose en un obstáculo para el desarrollo. Siguiendo las rutas de comercio establecidas entre los asentamientos de 
Norteamérica y las Indias occidentales, la fiebre amarilla arribó a Nueva York en 1668 aupada en las alas de los mosquitos $A$. aegypti que se criaban en los toneles de agua de los viejos barcos mercantes de madera. La epidemia de 1668 se describió como "particularmente destructiva en las ciudades de Nueva York y Filadelfia" (2). Entre 1668 y 1905, la fiebre amarilla regresaba cada verano desde Boston en el norte hasta Nueva Orleans y el valle del Mississippi, "diezmando poblaciones, paralizando la industria y el comercio y manteniendo a los pueblos de estas regiones en estado de terror permanente ante el temido Juan Amarillo" $(1,2)$. Entre 1668 y 1870, Nueva York sufrió no menos de 15 epidemias. Treinta fueron documentadas en Filadelfia entre 1668 y 1867, siendo la más devastadora la ocurrida en 1793. La epidemia se desató "justo después del arribo de refugiados de Santo Domingo en agosto y se extendió durante siete semanas" (2), con un resultado de cerca de 4.000 muertos. Cuando la fiebre amarilla invadió las planicies de Estados Unidos en 1846, "los mormones, durante su marcha de Nanvoo a Utah, sufrieron de fiebres remitentes y amarillas. Su avance a través del desierto quedó marcado por las tumbas de aquéllos que sucumbían a ellas" (30-32). La más devastadora de las 18 epidemias de fiebre amarilla ocurridas en Nueva Orleans entre 1811 y 1878 fue la de 1853 con cerca de 5.000 casos y 1.000 muertes. La ciudad de Charleston, Carolina del Sur, perdió a 682 de sus ciudadanos durante la epidemia de 1854 y sufrió el azote de, por lo menos, otras 15 epidemias entre 1690 y 1876. En el valle del Mississippi, la epidemia de 1878 causó la muerte de 13.000 personas y "su efecto paralizador en la economía resultó en pérdidas de más de cien millones de dólares" (2). El trabajo de Reed y sus colegas en la Comisión Rockefeller (2) apuntaba claramente a la erradicación del mosquito como el método práctico para exterminar la fiebre amarilla. Este principio fue acogido y experimentado por el gobierno de Cuba con resultados increíbles. En febrero de 1901 se comenzaron a poner en práctica medidas de eliminación del mosquito encaminadas a librar a la ciudad de $A$. aegypti y para septiembre de ese mismo año la fiebre amarilla había sido completamente erradicada. Este exitoso procedimiento se repitió en Panamá,
El Salvador, Nicaragua, Honduras, Guatemala, Ecuador, México, Perú, Colombia y Brasil. Para finales de 1924, la fiebre amarilla urbana había sido erradicada en muchos sitios de Centroamérica y Suramérica (2). Aunque desde la epidemia de 1905 en Nueva Orleans no se ha informado de casos de fiebre amarilla en Norteamérica, gran parte de la región suroriental de los Estados Unidos ha sido reinfestada con mosquitos $A$. aegypti, incrementando así la posibilidad de brotes de fiebre amarilla (23).

\section{Centro y Suramérica}

Los países de Centroamérica y Suramérica tampoco se libraron de la devastación de la fiebre amarilla (2,30-33). Entre 1649 y 1900, se documentaron más de cien epidemias en diferentes países de la región. El primer brote del cual se tiene noticia ocurrió en 1649 en las Indias occidentales entre las tropas europeas estacionadas allí. Alrededor de 31.000 personas murieron durante la epidemia. Otras epidemias importantes se produjeron en la Guayana Francesa en 1762, la cual se extendió durante tres años; la de San Juan en 1804, con una tasa de mortalidad descrita como 'excesiva' (34) y la de Rio de Janeiro en 1804, en la cual la mortalidad excedió el 95\% (35). Colombia y Venezuela $(30,31)$ padecieron brotes frecuentes entre 1907 y 1929. En 1949, los diez países más devastados por la fiebre amarilla (Brasil, Bolivia, Guayana Británica, Colombia, Ecuador, Guayana Francesa, Panamá, Perú, Surinam y Venezuela) lanzaron una vigorosa campaña de erradicación de $A$. aegypti. Para 1965, los criaderos urbanos de mosquitos habían sido destruidos y la fiebre amarilla erradicada de la mayoría de los asentamientos urbanos en América (33). Sin embargo, de 1985 a 1994 se informaron casos de fiebre amarilla selvática en Bolivia, Brasil, Colombia, Ecuador y Perú. Durante esa década se informaron, en promedio, 154 casos al año de fiebre amarilla selvática (rango: 88-237 casos) en Suramérica (23). En 1995, Perú informó un brote de fiebre amarilla selvática con 440 casos y una tasa de mortalidad de $38 \%$. Esta fue la epidemia más grande en Latinoamérica desde 1950. La fiebre amarilla urbana no se ha informado en las Américas desde 1954. No obstante, los 
mosquitos $A$. aegypti han reinfestado muchas ciudades tropicales de Suramérica, preparando así el terreno para la aparición de graves brotes de la enfermedad. El dengue, otro arbovirus transmitido por $A$. aegypti, ha reaparecido de manera acusada en las Américas con más de 200.000 casos informados en 27 países del Caribe y de Centro y Suramérica desde noviembre de 1995 (3).

\section{Europa}

La fiebre amarilla, una de las enfermedades más temidas durante el siglo XVII en las rutas del Atlántico, inspiró la leyenda del navío 'Holandés volador', destinado a navegar fantasmalmente alrededor del Cabo de la Buena Esperanza, pues el brote de fiebre amarilla que se desató a bordo impidió que se le diera entrada a ningún puerto y toda su tripulación pereció (33). Entre 1649 y 1878, se informaron 22 epidemias de fiebre amarilla en Europa, desde Gibraltar hasta Dublín (33). La fiebre amarilla fue importada a Gibraltar en 1649 en los barcos que iban y venían desde Africa y las Indias occidentales. La epidemia de 1723, tal vez el primer episodio de la enfermedad ocurrido en el corazón de Europa, se informó primero en Lisboa y prácticamente se extendió hasta Londres (33). Pero la que sin duda fue la más grande epidemia europea de la enfermedad comenzó en septiembre de 1730, cuando murieron 22.000 personas después del arribo de la flotilla de Pintado, proveniente de Cartagena, donde muchos de sus hombres habían perecido en manos del 'vómito prieto' $(30,34)$. Comentando sobre la epidemia, se dice que Bascome señaló "... seguramente ésa era la pestilencia que durante siete años, de 1729 al 35, azotó Viena, Pignrol Fossano, Niza, Rívoli, Asti, Larti, Acqui, Basilea, Silesia, Trasburgo (en el bajo Rin), Trino, Fresneuse (bajo Sena), Vimeux (Sena y Oise), Orleans (Loiret), Plouvirers (Loiret), Meaux, Villeneuve, St. George (Sena y Maine), Bohemia, Dinamarca, Suecia y Rusia $(1,35)$. Durante las operaciones militares de 1741 en Málaga, España, se informó sobre la muerte de 8.000 personas afectadas por la fiebre amarilla. Durante los siguientes 60 años, se informaron pocos brotes de la enfermedad en Europa, pero a comienzos del siglo XIX, la fiebre amarilla reapareció en España y Portugal. En 1821, se informó de no menos de 20.000 muertes causadas por la fiebre amarilla en España, de las cuales 5.000 ocurrieron en Barcelona $(1,35)$. La epidemia de 1857 en Oporto y Lisboa fue descrita como de proporciones "pasmosas tanto por su escala como por la mortalidad", constituyéndose en la última gran epidemia de la enfermedad en Europa. Otras epidemias de interés incluyen la de 1826 en Dublín, el punto más remoto afectado por brotes de fiebre amarilla en el continente, la de 1828 en Gibraltar, con más de 5.000 casos y 1.000 muertes; la de 1861 en Saint Nazare, Francia, traída a bordo del Anne Marie, un pequeño velero de madera procedente de La Habana que, antes de tocar puerto en Saint Nazare ya había alcanzado un $22 \%$ de mortalidad entre sus tripulantes debido a la fiebre amarilla $(1,35)$.

\section{Africa}

Ya desde 1494, diversas enfermedades de sintomatología parecida a la de la fiebre amarilla habían sido detectadas en islas frente a las costas africanas (Canarias, Cabo Verde, etc.) y en algunos países costeros como Gambia y Sierra Leona (1). Desde la segunda mitad del siglo XVIII, se han presentado a intervalos epidemias de fiebre amarilla en Africa, siendo la de 1778, ocurrida en Saint Louis, Senegal, entre los soldados británicos allí estacionados, el primer episodio documentado de la enfermedad (17). Los informes clínicos de la epidemia, publicados en 1782 , se leen como citas extraidas de las modernas novelas sobre enfermedades emergentes y exóticas: "... el vómito continuó. Después se tornó verde, pardo y, por último, negro, coagulándose en pequeños grumos. Una diarrea continua, acompañada de retortijones, se produjo a continuación, con la que se evacuó una gran cantidad de heces negras y pútridas. $\mathrm{La}$ piel, entonces, se llenó de petequias $(1,34)$. La investigación rigurosa de la fiebre amarilla comenzó en 1925 cuando la Fundación Rockefeller estableció laboratorios de fiebre amarilla en Ghana y Nigeria (2). Antes de que se diera inicio a las campañas masivas de inmunización en Africa, típicas epidemias de fiebre amarilla urbana ocurrían en diferentes sitios de Africa occidental y Sudán. Además, se daban también los casos de tipo selvático en las zonas boscosas. Aunque no existe información epidemiológica sobre estos 
brotes, hay informes de brotes de la enfermedad con miles de casos y muertes documentados en Nigeria (1925-1928), Ghana (1926-1927, 1937) y Gambia (1934-1936) (17). Entre 1940 y 1953, en el Africa occidental francoparlante, se aplicaron más de 40 millones de dosis de vacuna durante las jornadas obligatorias de inmunización (figura 2), lo cual resultó en la virtual desaparición de la fiebre amarilla de estas zonas, aunque se mantuvo como enfermedad endémica con brotes periódicos en otros países en los cuales no había programas de inmunización (16). La dismunición de casos notificados trajo como consecuencia una pérdida de interés en la enfermedad y un descuido creciente de los programas de vigilancia e inmunización en la segunda mitad de la década de 1950. Más aún, la producción y el uso de la vacuna se detuvo ante los informes de casos graves y fatales de encefalitis en niños menores de 12 años que habían recibido la vacuna (25). Cinco años después del cese de las campañas masivas de vacunación, los países africanos comenzaron a enfrentar brotes de la enfermedad. Entre 1958 y 1962, Zaire (hoy República Democrática del Congo), Sudán y Etiopía informaron graves brotes. Se estima que durante la epidemia de 1960-62 en Etiopía, se produjeron 100.000 casos y 30.000 muertes (17). De 1969 a 1995, las epidemias de fiebre amarilla asolaron en proporción variada diferentes regiones de Africa, siendo el periodo comprendido entre 1988 y 1990 el de mayor actividad del virus. Con un total mundial de 8.685 casos y 2.643 muertes durante esos tres años y a pesar de existir un subregistro considerable, ese periodo representó el mayor número de casos y muertes informadas a la OMS desde 1948, cifra de la cual el $90 \%$ de casos y muertes correspondió a los países africanos. En 1992, la enfermedad apareció más hacia el oriente, en Kenia, país que se había visto libre de la enfermedad desde 1950. Gracias a un sistema mejorado de vigilancia por el laboratorio, Kenia detectó casos de la enfermedad en 1994 y 1995. En 1996, cinco países africanos, Benin, Burkina Faso, Ghana, Liberia y Nigeria informaron 1.132 casos de fiebre amarilla. Las epidemias recientes en Africa han afectado fundamental-mente a niños menores de 15 años $(15,16)$, debido a que muchos países del continente abandonaron las campañas masivas de vacunación a partir de 1960 y optaron por jornadas focalizadas de respuesta a emergencias (26). El $62 \%$ de los 4.661 casos informados en Africa entre 1965 y 1991 afectaron a los niños. En Senegal, Burkina Faso y Camerún más del $80 \%$ de los casos se dieron entre la población infantil. Durante los primeros seis años de la década del 90, Africa notificó 9.876 casos de fiebre amarilla, lo que representa más del $70 \%$ del número total de casos notificados durante toda la década del 80 .

Tradicionalmente, los países africanos en riesgo han recurrido al enfoque de 'apagar incendios' al enfrentar los brotes recientes de la enfermedad, a menudo con resultados desastrosos. Además del gran número de muertes prevenibles, este enfoque ha afectado seriamente los ya frágiles servicios de salud, produciendo un gran desperdicio de vacuna y ejerciendo una presión inusual en los recursos materiales y humanos provenientes de los presupuestos nacionales y de las donaciones. Por ejemplo, para enfrentar una epidemia devastadora ocurrida entre 1986 y 1991, Nigeria importó más de 30 millones de dosis de vacuna. Sin embargo, el país no pudo contener la epidemia rápida y efectivamente porque su capacidad para utilizar de manera efectiva las dosis importadas quedó sobrepasada, lo que llevó al desperdicio de más del $30 \%$ de las vacunas; los servicios de salud fueron copados por la lucha contra la epidemia generalizada y las jornadas de vacunación siempre se retrasaban con respecto a los brotes en tres 0 cuatro meses, por lo menos. Como consecuencia, la importación masiva de dosis de vacuna tuvo muy poco efecto sobre la epidemia que se extendió sin obstáculos durante más de cuatro años a lo largo de todas las regiones del país. Son ingentes los recursos movilizados para hacer frente a las campañas de inmunización de emergencia ante los informes de epidemias en Nigeria, Liberia, Benín y otros países, debido a la ausencia de programas regulares de vacunación. Se estima que tratar de controlar epidemias a través de campañas de vacunación de emergencia resulta, al menos, siete veces más costoso que la introducción de la vacunación infantil con programas regulares (36). El peso real de la enfermedad, tanto en medio de las epidemias 
como cuando éstas remiten, no ha sido calculado de manera precisa ya que los sistemas de vigilancia no son lo suficientemente sensibles en los países con fiebre amarilla endémica. Después de la epidemia de 1986 en Nigeria, dos de las poblaciones afectadas fueron abandonadas y los pobladores se desplazaron hacia pueblos vecinos. Cuatro años más tarde, los pueblos permanecían desiertos, pues sus habitantes se rehusaban a regresar. Con el resurgimiento de la enfermedad durante las últimas dos décadas, especialmente en Africa, la fiebre amarilla ha continuado diezmando poblaciones y causando estanca-miento económico y más subdesarrollo. Tal vez el aspecto más inquietante de las recientes epidemias de la enfermedad en Africa es que han afectado prioritariamente a la población menor de 15 años $(15,16)$. La falta de conciencia por parte de los gobiernos y las autoridades de salud en las regiones endémicas del mundo sobre el impacto real de la enfermedad sobre su desarrollo representa una tragedia de nuestra época. $Y$ es una tragedia inexcusable, sabiendo que existe una vacuna segura y efectiva, probada durante más de 60 años, $y$, particularmente, porque la enfermedad fue controlada en el pasado a través de las jornadas de vacunación llevadas a cabo en los países del continente bajo el mandato colonial francés entre 1939 y $1963(3,28)$.

\section{La fiebre amarilla en Asia}

Ya desde 1934, se ha venido expresando preocupación por la posibilidad de la diseminación de la fiebre amarilla desde Africa oriental hacia Asia (37). A pesar de la aparición de epidemias de la enfermedad en 1940 en Sudán (37), de 1960-62 en Etiopía (39) y de 1992-93 en Kenia (40,41), Asia ha logrado mantenerse libre de la enfermedad. Son numerosas las razones que se han aducido para explicar el hecho de que la fiebre amarilla no se haya extendido a Asia: 1) el virus no se ha introducido en Asia; 2) la variación de la susceptibilidad humana a la fiebre amarilla; 3 ) diferencias en la competencia o comportamiento del vector; 4) protección cruzada entre los Flavivirus y 5) ausencia de un ciclo de mantenimiento. Ninguna de ellas, sin embargo, explica suficientemente el fenómeno. No obstante, aunque la enfermedad no se ha extendido aún a Asia, todavía puede ocurrir, por lo que los países asiáticos deben continuar exigiendo que todo visitante de países endémicos porte un certificado válido de vacunación contra la fiebre amarilla.

\section{Factores responsables de la reemergencia de la fiebre amarilla}

Algunos de los factores responsables del resurgimiento de esta enfermedad, y en realidad de otras, especialmente en Africa, incluyen los siguientes (42): el colapso de los sistemas de servicios de salud; la vigilancia débil o inadecuada de la enfermedad; las medidas inapropiadas de control; la pobreza urbana acompañada de asentamientos hacinados y desplazamientos masivos de población; el manejo inadecuado del medio ambiente y la deforestación creciente.

Las epidemias a menudo se inician en las áreas rurales, alejadas de los centros urbanos y de la sede de las autoridades nacionales responsables de la toma de medidas de control, de manera que la detección y la notificación de las epidemias ocurre generalmente dos o tres meses después de su inicio.

Allí donde se notifica un brote con prontitud, ocurre que la confirmación del diagnóstico clínico o presuntivo es por lo general imposible, debido a la ausencia de una red adecuada de laboratorios estatales de diagnóstico. Más aún, cuando se dispone de confirmación por el laboratorio, las autoridades responsables son incapaces de responder oportuna y apropiadamente con la adopción de las medidas de control necesarias. En muchos países en desarrollo, los sistemas y la infraestructura de salud han estado sujetos a años de negligencia, lo que resulta en la escasez de equipo básico y suministros y la baja moral del personal a cargo. Ante esta situación, las instituciones de salud son incapaces de brindar los cuidados necesarios a los enfermos y ello ha llevado a que la comunidad busque atención médica alternativa, incrementando así el riesgo de diseminación de la enfermedad, pues los enfermos pasan a ser cuidados por miembros de la propia familia. Se han propuesto dos enfoques para el control de la fiebre amarilla: campañas masivas de vacunación e inclusión de la vacuna contra la fiebre amarilla en los esquemas 
regulares del programa PAI. Desde el resurgimiento de la enfermedad en Africa, sólo Gambia, entre los 34 países en riesgo de epidemias en el continente, ha adelantado con éxito una campaña masiva de vacunación, logrando coberturas de 95\%. Diecisiete de los 34 países decidieron incluir la vacuna en el esquema nacional del PAI con diversos grados de efectividad. Una de las razones que a menudo se aduce para explicar el lamentable estado de la salud en Africa es el nivel de subdesarrollo resultante de la pobreza generalizada. De hecho, la pobreza aunada a la ignorancia sí es responsable de la aparición y la gravedad de la mayoría de las enfermedades infecciosas en el continente. En Africa, la pobreza se manifiesta de formas diversas, trayendo como consecuencia el desplazamiento masivo de poblaciones hacia los centros urbanos ya de por sí superpoblados, en los cuales los estándares sanitarios son deplorables. La búsqueda de alimento y de medios de supervivencia y la escasez y competencia por el acceso a tierras cultivables lleva a la invasión de territorios vírgenes y a la extensión de las zonas infestadas con fiebre amarilla, debido al pésimo manejo ambiental. La epidemia de 1994 en Gabón ilustra lo señalado: la epidemia comenzó como un brote de tipo selvático en un remoto campo minero y poco después se extendió rápidamente hacia los poblados, en donde se hizo evidente el cambio al tipo urbano por la presencia de mosquitos $A$. aegypti (42). Mientras exista pobreza en el mundo en desarrollo es necesario enfatizar que ello a menudo no se debe a falta de recursos materiales y humanos, sino más bien a prioridades equivocadas o mal orientadas. Por ejemplo, entre 1990 y 1995, el gasto militar y de defensa en muchos de los países en desarrollo osciló entre 15 y 273 puntos más que lo asignado conjuntamente a salud y educación (43).

\section{Control de la fiebre amarilla}

¿Cuáles son las opciones disponibles para el control de la fiebre amrilla en los países en desarrollo? Recientemente, la OMS lanzó una iniciativa para combatir la dramática reemergencia de la enfermedad en Africa y controlarla en el año 2000. La iniciativa, coordinada con los ministerios de salud nacionales, integraría esfuerzos de asociación con agencias bilaterales, otros organismos de las Naciones Unidas y con organizaciones no gubernamentales (44). Las dos metas propuestas eran la introducción, fijada para 1997, de la vacuna contra la fiebre amarilla en los programas de inmunización infantil en todos los 34 países en riesgo y lograr para el año 2000 , al menos, $80 \%$ de cubrimiento de la vacuna en la población infantil menor de cinco años en esos 34 países. Cuatro eran las estrategias propuestas para lograr esos objetivos (29): inmunización, mejoramiento de la vigilancia, prevención de brotes y respuesta a brotes. La promoción de estrategias de inmunización efectivas, tanto regulares como suplementarias, es esencial para el control de la fiebre amarilla en los 34 países africanos en riesgo. En 1988, el Grupo Técnico de Inmunizaciones conjunto Unicef/OMS en Africa recomendó que la vacunación contra la fiebre amarilla se integrara a los programas de inmunización en los 34 países con riesgo de epidemias de la enfermedad (29). Los programas nacionales de inmunización debían aplicar las estrategias necesarias para lograr y sostener en cada distrito, al menos, $80 \%$ de cubrimiento al año de edad de todas las vacunas del esquema, incluida la de fiebre amarilla. Sin embargo, la financiación de la vacuna contra la fiebre amarilla ha sido un obstáculo muy serio para lograr estas metas. Aunque 17 países han adoptado la estrategia, sólo 13 (Angola, Burkina Faso, República Centroafricana, Chad, Costa de Marfil, Gabón, Gambia, Malí, Mauritania, Nigeria, Senegal y Togo) pudieron obtener los fondos y procurarse la vacuna. El cubrimiento ha oscilado entre un $87 \%$ en Gambia y $1 \%$ en Nigeria, y sólo dos países habían logrado superar el $50 \%$ de cubrimiento con la vacuna en 1995. La experiencia de Gambia es un ejemplo del éxito de esta estrategia. Después de la epidemia de 1978-79 y de la exitosa campaña de vacunación masiva llevada a cabo durante esos años, con la cual se vacunó el $95 \%$ de la población mayor de seis meses con una dosis, la vacuna de fiebre amarilla se añadió al PAI en Gambia. La vacuna se administraba en el momento en que los niños eran vacunados contra el sarampión. Desde entonces, Gambia ha mantenido un cubrimiento de más del $80 \%$ y no ha notificado un solo caso de la 
enfermedad, y ello cuando se han notificado casos en Senegal, un país que prácticamente rodea a Gambia. Además de la introducción efectiva y el logro de altos cubrimientos con la vacuna contra la fiebre amarilla en niños, la enfermedad puede controlarse si se llevan a cabo campañas de inmunización masiva en un periodo de cinco a diez años. La duración de dichas campañas en el grupo objeto de ellas depende de la epidemiología de la enfermedad en cada país en riesgo.

Todos los países en riesgo requieren de un sistema continuo y sensible de vigilancia para la detección temprana de casos como prerrequisito para la respuesta rápida de contención de brotes potenciales. Los laboratorios con capacidad para el diagnóstico diferencial son esenciales dadas las dificultados en la diferenciación de la fiebre amarilla de otras enfermedades con síntomas similares como la hepatitis, la malaria, la fiebre tifoidea y otras ictericias febriles. La Región Africana, demarcada así por la OMS, está fortaleciendo el sistema de vigilancia con el fin de lograr la notificación oportuna y completa de las enfermedades prioritarias y la monitorización de indicadores estandarizados. Desde 1994, la OMS, en colaboración con otros organismos, ha organizado cursos de capacitación en diagnóstico de la enfermedad y medición de la potencia de la vacuna, a los cuales han asistido más de 80 técnicos y científicos provenientes de laboratorios de 20 países africanos. El personal capacitado regresa a sus países con suministros y medios de diagnósticos. Para fortalecer las capacidades de diagnóstico, se planifican cursos de capacitación y actualización para patólogos de la región encaminados a mejorar las capacidades diagnósticas basadas en la histopatología.

La meta fundamental de la nueva estrategia de la OMS para el control de la fiebre amarilla es expandir rápidamente el cubrimiento con la vacuna en Africa, ligándola a las campañas masivas de vacunación contra la poliomielitis y el sarampión, a la vez que se incluye en los programas regulares de inmunización infantil. El éxito de la vacunación masiva en Africa occidental en las décadas del 40 y el 50 , subraya la efectividad de lograr altos cubrimientos en la población. Los anticuerpos que se adquieren por la infección natural o por la vacunación probablemente persisten a lo largo de toda la vida. Definitivamente, se requiere impulsar campañas masivas de vacunación contra la fiebre amarilla en los países en riesgo. Ya que se necesitan millones de dosis de la vacuna para lograr mínimo un $80 \%$ de cubrimiento tanto en poblaciones rurales como urbanas, se debe promover el aumento de la producción entre las compañías productoras de la vacuna.

Las medidas para el control rápido de las epidemias se ven obstaculizadas por el reconocimiento y notificación tardíos. La OMS está asesorando a los países en la ejecución de acciones que mejoren la respuesta apropiada a los brotes de fiebre amarilla, entre las cuales se incluyen la recolección y estudio de especímenes; la investigación de la epidemia para determinar su alcance; la investigación entomológica y el control de vectores, y la aplicación de medidas para prevenir la diseminación del virus de pacientes a mosquitos. La vacunación de emergencia en poblaciones en riesgo se hace posible gracias a la existencia de la vacuna, que la OMS mantiene y que puede distribuirse rápidamente en caso de aparición de brotes.

\section{Conclusiones}

¿Por qué la fiebre amarilla sigue constituyendo un serio problema de salud pública en el mundo en desarrollo y, especialmente, en Africa? ¿Por qué, a pesar de lo que sabemos del virus y de contar con una vacuna eficaz y segura, la enfermedad no ha podido controlarse? ¿Por qué la comunidad internacional, tan dispuesta a inundar a Africa con ayuda en forma de vacunas y apoyo logístico cuando se presenta una epidemia, se muestra tan reacia cuando se trata de la prevención de la enfermedad a través de la ayuda a la vacunación infantil regular y de otras medidas preventivas? ¿Por qué los gobiernos de los países en desarrollo se muestran tan despreocupados ante los efectos devastadores de la enfermedad? Si la meta es controlarla, estas preguntas deben encontrar respuesta. Un informe sobre la epidemia de fiebre amarilla que asoló a Senegal y Gambia en 1748 dice en una de sus apartes: "... en varios poblados, entre la población negra la mortalidad 
fue de tal magnitud que no había suficientes sobrevivientes para enterrar a los muertos" (3). Ciento treinta y cinco años después, en otra parte de Africa, el jefe de un poblado diezmado por la fiebre amarilla dio la bienvenida a nuestro equipo de investigadores casi con las mismas palabras: "De haber llegado cuatro semanas antes, los jóvenes y los pobladores sanos hubieran salido a darles la bienvenida con gestos tradicionales de hospitalidad. Ahora, sus cuerpos yacen sin sepultura porque sólo los viejos quedan y están muy débiles de cuerpo y espíritu para enterrar a sus jóvenes y... a su futuro". La tragedia de esta enfermedad en el mundo en desarrollo, y en especial en Africa, pasa por la falta de conciencia sobre sus efectos destructivos en el desarrollo económico y social de amplios segmentos de la población por parte de los gobiernos y las autoridades de salud. En la mayoría de los países africanos existe una indiferencia criminal en torno al control de la enfermedad entre los gobernantes y la élite culta, que sólo se preocupan por proteger a sus propias familias y amigos con la vacuna, descuidando a las masas de pobladores rurales y de residentes de los cinturones de miseria alrededor de las ciudades. La responsabilidad por la iniciativa de control de la fiebre amarilla recae en los gobiernos nacionales y en las comunidades de los países en riesgo. Los recursos humanos y materiales necesarios para el control de la fiebre amarilla existen en estos países tanto como las epidemias de la enfermedad. El fracaso en el control de la enfermedad en los países en desarrollo no lo es tanto de la salud pública como resultado de la aplicación equivocada de las estrategias establecidas. Para controlar la fiebre amarilla y su impacto no sólo en los países endémicos sino en el mundo entero, los gobiernos de los países endémicos deben liderar la iniciativa, reordenar sus prioridades y apoyar las actividades de vigilancia y control a través del compromiso político y presupuestal. Los organismos internacionales también deben reordenar sus prioridades en términos del alcance y la modalidad del apoyo que prestan en el control de la enfermedad. Sólo entonces podremos albergar la esperanza y la confianza con que Major Gorgas se expresó sobre la enfermedad en 1902 (1).

\section{Referencias}

1. Augustin G. History of yellow fever. New Orleans: Searcy and Pfaff Ltd.; 1909.

2. Strode GK, editor. Yellow fever. New York: McGraw Hill Book Company Inc.; 1951.

3. Robertson SE, Hull BP, Tomori O, Okwo B, LeDuc JW, Esteves K. Yellow fever: a decade of reemergence. JAMA 1996;276:1157-62.

4. Groot H. Abstracts. XV International Congress for Tropical Medicine and Malaria. Cartagena de Indias, Colombia, August 20-25, 2000. Cartagena: Universidad de los Andes, Instituto de Inmunología, Corporación para Investigaciones Biológicas, Sociedad Colombiana de Parasitología y Medicina Tropical; 2000. p.155-6.

5. Smith A. Yellow fever in Galveston, Republic of Texas, 1839. Austin, Texas: University of Texas Press; 1951.

6. Finlay CJ. Yellow fever: its transmission by means of the Culex mosquito. Am J Med Sci 1886;92:395.

7. Kelly HA. Walter Reed and yellow fever. New York: McClune, Phillips \& Co.; 1907.

8. Soper FL. Jungle yellow fever: new epidemiological entity in South America. Rev Hyg Saude Publica 1936; 10:107-44

9. Haddow AJ, Gillette JD, Highton RB. Yellow fever. Bull Ent Res 1947;37:301.

10. Germain M, Cornet M, Mouchet J, et al. Recent advances in research regarding sylvatic yellow fever in West and Central Africa. Bull Inst Pasteur 1982; 80:31530.

11. Theiler M, Smith HH. Use of yellow fever modified by an in vitro cultivation for human immunization. J Exp Med 1937;29:62-4.

12. Theiler $\mathbf{M}$. The development of vaccines against yellow fever - Les Prix Nobel de 1951. En: Collected papers by members of the staff. New York: Division of Medicine and Public Health of the Rockefeller Foundation; 1952.

13. Stokes A, Bauer JH, Hudson NP. Transmission of yellow fever to Macacus rhesus: preliminary note. JAMA 1928;90:253-4.

14. Stokes A, Bauer JH, Hudson NP. Experimental transmission of yellow fever to laboratory animals. Am J Trop Med 1928;8:103-64.

15. UNICEF/WHO. Joint Technical Group on Immunization for the African Region. Report of the Third Meeting, Nairobi; 1988.

16. Tomori O, Nasidi A, Mung K. Status of yellow fever vaccination in the Expanded Programme on Immunization (EPI). En: Proceedings of the 4th. International Seminar on Immunization in Africa, Yamoussoukro, Cote d'Ivoire. Lyon: Foundation Marcel Merieux; 1994. p.107-12. 
17. World Health Organization. Prevention and control of yellow fever in Africa. Geneva: WHO; 1986.

18. Monath TP, Heinz FX. Flaviviruses. En: Fields BN, Knipes DM, Howley PM, Chanock RM, Melnick JL, Monath JL, Roizman B, Straus SE, editors. Field's Virology. Third edition. Philadelphia: Lippincott-Raven Publishers; 1995. p.961-1034.

19. Clarke DH. Antigenic analysis of certain group B arthropod-borne viruses by antibody absorption. J Exp Med 1960;111:21-32.

20. Fitzgeorge $\mathbf{R}$, Bradish CJ. The in vivo differentiation of strains of yellow fever virus in mice. J Gen Virol 1980; 46:1-14.

21. Chang GJ, Cropp CB, Kinney RM, Trent DW,Gubler DJ. Nucleotide sequence variation of the envelope protein gene identifies two distinct genotypes of yellow fever virus. J Virol 1995;69:5773-80.

22. Deubel V, Digoutte JP, Monath TP, Girard M. Genetic heterogenecity of yellow fever virus strains from Africa and the Americas. J Gen Virol 1986;67: 209-13.

23. Monath TP. Yellow fever: Victor, Victoria? Conqueror, Conquest? Epidemics and research in the last forty years and prospects for the future. Am J Trop Med Hyg 1991:45:1-43.

24. Rice CM, Lenches EM, Eddy SR, Shin SJ, Sheets RL, Strauss JH. Nucleotide sequence of yellow fever virus: implication for flavivirus gene expression and evolution. Science 1985;229:726-35.

25. Monath TP. Yellow fever. En: Warren KS, Mahmoud AAF, editors.Tropical and geographical medicine. Second edition. New York: Mc Graw Hill Inc.; 1990. p.66174.

26. Robertson SE. Yellow fever: the immunological basis for immunization. Geneva: World Health Organization; 1993.

27. Durieux C. Preparation of yellow fever vaccine at the Institut Pasteur, Dakar. En: Smithburn KC, Durieux C, Koerber MD, Penna GWA, Courtois D, editors. Yellow fever vaccination. Geneva: WHO; 1956. p.31-2.

28. Durieux C. Mass yellow fever vaccination in French Africa south of the Sahara. En: Smithburn KC, Durieux C, Koerber MD, Penna GWA, Courtois D, editors. Yellow fever vaccination. Geneva: WHO; 1956. p.115-21.

29. WHO. Global Programme for Vaccines and Division of Emerging and other Communicable Diseases. A framework for control of yellow fever in Africa. Geneva: WHO; 1956.
30. Hobson W. World health and history. Bristol: Wright; 1963.

31. Carter HR. Yellow fever: an epidemiological and historical study of its place of origin. Baltimore: Williams and Wilkins Co.; 1931.

32. Busvine JR. Disease transmission by insects: its discovery and ninety years of efforts to prevent it. New York: Springer-Verlag; 1993.

33. Maurice J. Yellow fever makes comeback. Soumen Laakarilehti 1993;48:3057-61.

34. Scott HH. A history of tropical medicine. London: Edward Arnold and Co.; 1942

35. Vainio J, Cutts F. Yellow fever: working document for yellow fever technical concensus meeting, EMC/GPV/ EPI. Geneva: WHO; 1998.

36. Monath TP, Nasidi A. Should yellow fever vaccine be included in the Expanded Program of Immunization in Africa? A cost-effectiveness analysis for Nigeria. Am J Trop Med Hyg 1993;48:274-99.

37. Duddley SF. Can yellow fever spread into Asia? An essay on the ecology of mosquito-borne disease. J Trop Med Hyg 1934;37:273-8.

38. Mahaffy AF, Hughes TP, Smithburn KC,Kirk R. Isolation of yellow fever virus in Anglo-Egyptian Sudan. Ann Trop Med Parasitol 1941;35:141-8.

39. World Health Organization. Annual epidemiological and vital statistics. Geneva: WHO; 1964

40. World Health Organization. Yellow fever. Wkly Epidemiol Rec 1995;70:175-6.

41. World Health Organization. Yellow fever. Wkly Epidemiol Rec 1996;71:103.

42. Tomori O. Factors in the reemergence of yellow fever in West Africa. En: Saluzzo JF, Dodet B, editors. Factors in the emergence of arbovirus diseases. Paris: Foundation Marcel Merieux; 1997. p.167-73.

43. UNICEF. Progress of the Nations. New York: UNICEF; 1997.

44. World Health Organization. WHO appeals for action to combat dramatic resurgence of yellow fever in Africa. WHO Press Release 1996;67.

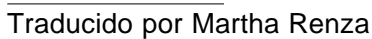




\title{
Yellow fever in Africa: public health impact and prospects for control in the 21st century
}

\author{
Oyewale Tomori* \\ WHO Region, Belvedere, Harare, Zimbabwe
}

In the last two decades, yellow fever re-emerged with vehemence to constitute a major public health problem in Africa. The disease has brought untold hardship and indescribable misery among different populations in Africa. It is one of Africa's stumbling blocks to economic and social development. Despite landmark achievements made in the understanding of the epidemiology of yellow fever disease and the availability of a safe and efficacious vaccine, yellow fever remains a major public health problem in both Africa and America where the disease affects annually an estimated 200,000 persons causing an estimated 30,000 deaths. Africa contributes more than $90 \%$ of global yellow fever morbidity and mortality. Apart from the severity in morbidity and mortality, which are grossly under reported, successive outbreaks of yellow fever and control measures have disrupted existing health care delivery services, overstretched scarce internal resources, fatigued donor assistance and resulted in gross wastage of vaccines. Recent epidemics of yellow fever in Africa have affected predominantly children under the age of fifteen years.

Yellow fever disease can be easily controlled. Two examples from Africa suffice to illustrate this point. Between 1939 and 1952, yellow fever virtually disappeared in parts of Africa, where a systematic mass vaccination programme was in place. More recently, following the 1978-1979 yellow fever epidemic in the Gambia, a mass yellow fever vaccination programme was carried out, with a $97 \%$ coverage of the population over 6 months of age. Subsequently, yellow fever vaccination was added to the EPI Programme. The Gambia has since then maintained a coverage of over $80 \%$, without a reported case of yellow fever, despite being surrounded by Senegal which experienced yellow fever outbreaks in 1995 and 1996.

The resurgence of yellow fever in Africa and failure to control the disease has resulted from a combination of several factors, including: 1) collapse of health care delivery systems; 2) lack of appreciation of the full impact of yellow fever disease on the social and economic development of the affected communities; 3) insufficient political commitment to yellow fever control by governments of endemic countries; 4 ) poor or inadequate disease surveillance; 5) inappropriate disease control measures, and 6) preventable poverty coupled with misplaced priorities in resource allocation.

Yellow fever can be controlled in Africa within the next 10 years, if African governments seize the initiative for yellow fever control by declaring an uncompromising resolve to control the disease, the governments back up their resolve with an unrelenting commitment and unwavering political will through adequate budgetary allocations for yellow fever control activities, and international organisations, such as WHO, UNICEF, GAVI, etc., provide support and technical leadership and guidance to yellow fever at risk countries. Over a ten-year period, of stage-bystage mass yellow fever vaccination campaigns, integrated with successful routine immunisation, Africa can bring yellow fever under control. Subsequently, for yellow fever to cease being a public health problem, Africa must maintain at least an annual $80 \%$ yellow fever vaccine coverage of children under the age of 1 year, and sustain a reliable disease surveillance system with a

*Invited author for review article 
responsive disease control programme. This can be achieved at an affordable annual expenditure of less than US\$1.00 per person per year, with a reordering of priorities.

Key words: yellow fever, epidemiology, prevention and control, history, Africa, America

\section{Historical review}

Yellow fever (YF) is a disease of antiquity that has been called by as many names as the countries where the disease has been reported. According to Augustin (1909), "no disease under heaven has had more synonyms than yellow fever" (1). Beginning in 1494, when it was generally designated by the name 'contagion', it had by 1907 acquired 152 synonyms including American Pestilence, Barbados Distemper, Continua Putrida Icteroides Caroliniensis, Yellow Jack, etc. However, the term yellow fever, by which the disease is now known was first used by Griffin Hughes in 1750 in his Natural history of Barbadoes (1750)(2). While the origin is subject to much controversy, it is generally agreed that yellow fever disease originated in either of the two areas of the world, Africa and America, where it is currently endemic (3) (figure 1).

The earliest epidemics of YF occurred in Barbados, Cuba, Guadeloupe and Mexico between 1647 and 1649. For the next two centuries, tropical and subtropical America continued to suffer recurrent large urban epidemics of YF which "decimated populations, paralyzed industry and trade and held the people of the region in a state of endless fear of the Yellow Jack" (2). The disease was spread by trade ships to US ports, reaching New York (1668), Boston (1691) and Charleston, North Carolina (1699). As late as 1905, YF accounted for 5,000 cases and 1,000 deaths in port cities of southern United States. During the eighteenth century, the disease appeared in Italy, France and Spain. In 1800, over 60,000 deaths were associated with the Spanish YF epidemic (2).

Yellow fever has often changed the course of history. This was the case of the British attack on

\footnotetext{
Correspondencia:

Oyewale Tomori

WHO Office, P. O. Box BE 773

Belvedere, Harare, Zimbabwe

tomorio@whoafr.org or tomorioyewale_@hotmail.com

Received: 19/04/02; accepted: 26/04/02
}

Cartagena in 1741 intended to destroy the Spanish power in the Caribbean. Arrayed against the Spanish military forces of 6 ships and 2.700 men were the overwhelming invading forces of the British force of 124 ships and 23,000 men (4). The silent ally of the Spaniards was yellow fever. Soon after their arrival to engage the Spaniards, the 'virgin' British soldiers became victims of the defenders guns as well of disentery and yellow fever; many of them started feeling feverish and developed a headache. Nausea and vomiting soon set in, with backache muscle pains. In many cases, the disease progressed to jaundice, with injected conjunctiva, and hemorrhage. At the end, the British not only lost the war, but also 8,400 men, representing approximately $37 \%$ of the army, and close to $50 \%$ of their men convalescing from the devastation and ravages of disease. On the other hand, the Spaniards, many of whom were not strangers to yellow fever, lost only 600 men, about $22 \%$ of their forces. But for YF outbreak of 1741 in Cartagena, today Colombia might have been under the influence of Britain, and the language of expression, English, instead of Spanish.

Epidemics of YF probably occurred in Africa much earlier than the documented outbreak of 1778, which reportedly decimated English troops stationed at Saint Louis, Senegal $(1,3)$. It was, however, not until 1925 that serious investigations of the disease began in West Africa. In 1848, Josiah Nott, first floated the idea that mosquitoes may be serving as agents for the dissemination of both yellow fever and malaria (5). However, the full credit for the theory of mosquitoes as vectors for yellow fever transmission was given to Carlos Finlay of Havana, Cuba, who in 1881, proposed the theory in a paper presented before the Royal Academy at its session in Havana $(1,2,6)$. Reed and colleagues later demonstrated that yellow fever is caused by a filterable agent, and that Aedes aegpti mosquitoes could transmit the disease (7). Following the successful eradication of yellow fever in Havana and Panama at the beginning of 


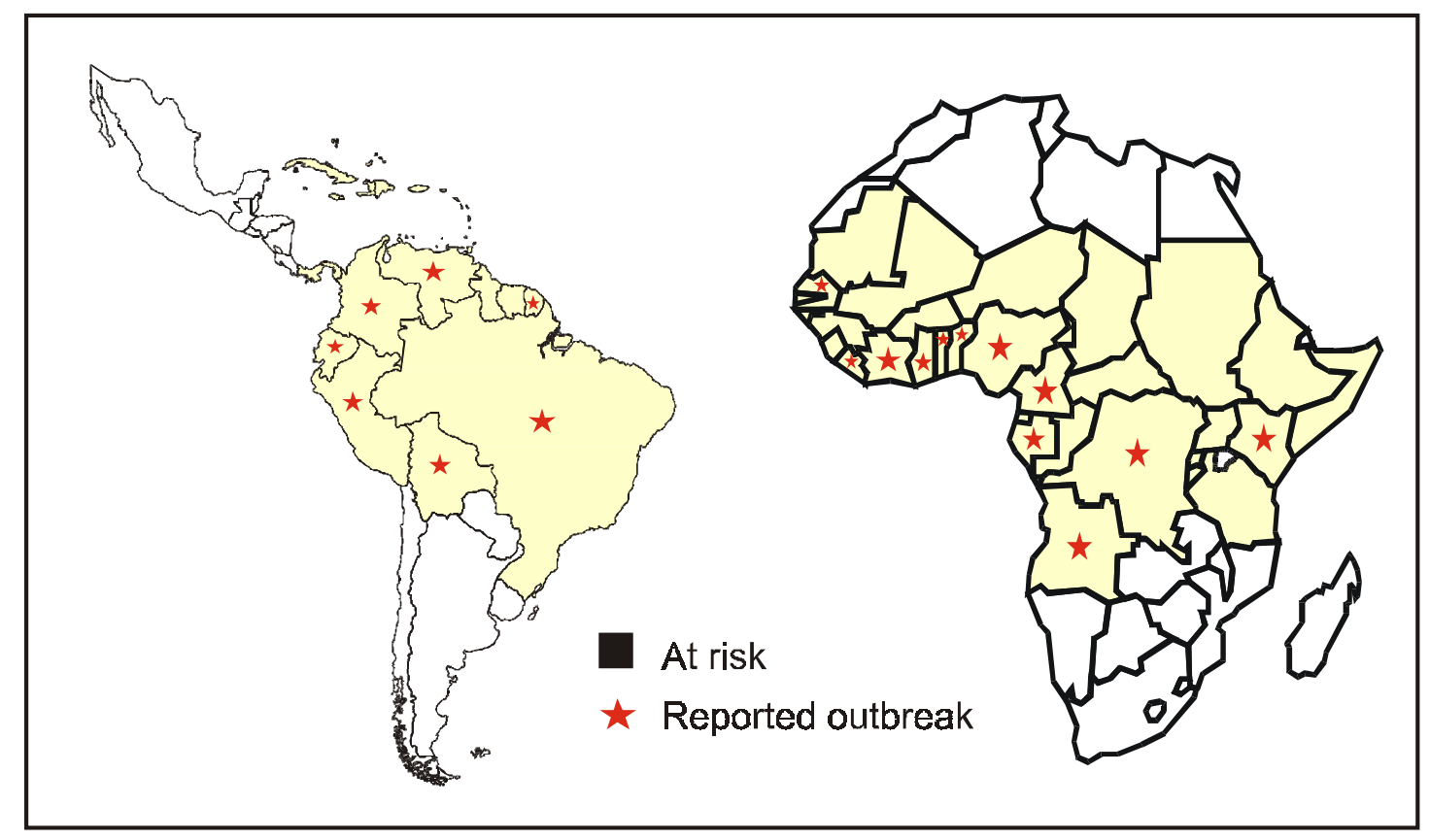

Figure 1. Countries at risk for yellow fever and having reported at least one outbreak, 1985 - 1999.

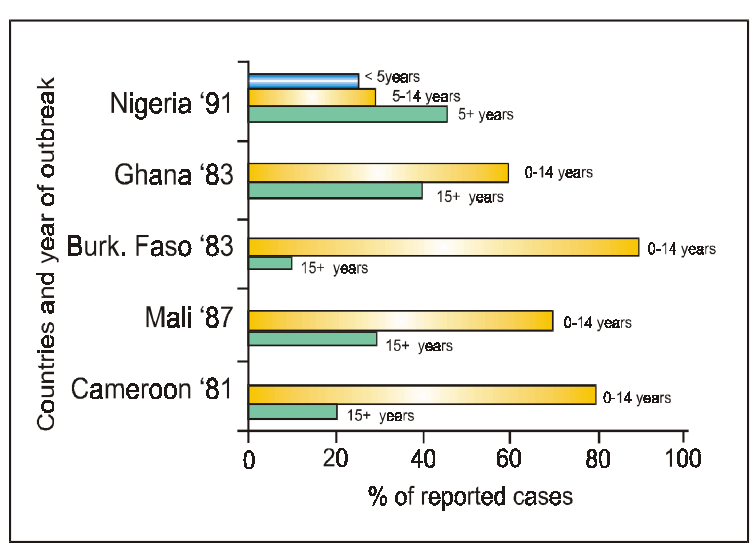

Figure 2. Age distribution of reported yellow fever cases during selected outbreaks, 1981-1991.

1900s, through anti-mosquito measures $(1,2)$, it was widely believed that $A$. aegypti mosquito was exclusively responsible for the transmission of yellow fever. It took the studies of Soper and coworkers to correct this widely held opinion (8). Their findings, later confirmed in other parts of the tropics $(9,10)$ resulted in the elucidation of the concept of jungle yellow fever transmission involving wild monkeys and sylvatic mosquito species, and the realization that it would take more than antimosquito measures to control yellow fever. In 1927, Mahaffy and Bauer of the Rockefeller Yellow Fever Commission (RYFC), isolated yellow fever virus by inoculating the blood of a Ghanaian patient into rhesus monkeys (2). This strain, the Asibi strain, was attenuated by passage in chick embryo tissue and the modified (17D) virus later became the source of human YF vaccine $(11,12)$. In other studies $(13,14)$, the staff of RYFC confirmed that:1) the causative agent of YF was a filterable virus; 2) the infection was easily transmitted from man to monkey or from monkey to monkey, by injection of citrated blood taken early in the disease; 3 ) that once infected, mosquitoes remained infective for life, which could be as long as 3 months or more, and 4) the bite of a single infected mosquito was sufficient to produce a fatal infection in a monkey.

Despite these landmark achievements in the understanding of the epidemiology of YF disease and the availability of a safe and efficacious vaccine, YF remains a major public health problem in both Africa and America where annually, the disease affects an estimated 200,000 persons causing an 
estimated 30,000 deaths (3). Recent epidemics of YF in Africa have affected predominantly children under the age of fifteen years (15-17) (figure 2).

\section{The virus}

Yellow fever virus belongs to the Flavivirus genus of the Flaviviridae family (18). It is the prototype of the genus, and the family contains over 70 related but distinct viruses, most of which are arthropod borne (19). Other major pathogens in the family are dengue viruses and Japanese encephalitis virus. Yellow fever virus is antigenically closely related to Banzi, Wesselsbron, Bouboui, Zika and Uganda S viruses, all, members of the flaviviridae family indigenous to Africa (19). Antigenic differences have been shown between strains of yellow fever virus. Polyclonal antibody-absorption techniques and virulence characteristics for mice have been used to distinguish between American and African YF virus strains, and between 17D vaccine and the parent Asibi viruses $(19,20)$. Electrophoretic migration patterns and carbohydrate content of protein $E$ has also been used to distinguish between African and American strains of yellow fever virus $(21,22)$. These studies identify only two yellow fever genotypes in Africa, and one or possibly two in South America. The two African genotypes are represented by the West African and the Central and East African virus strains.

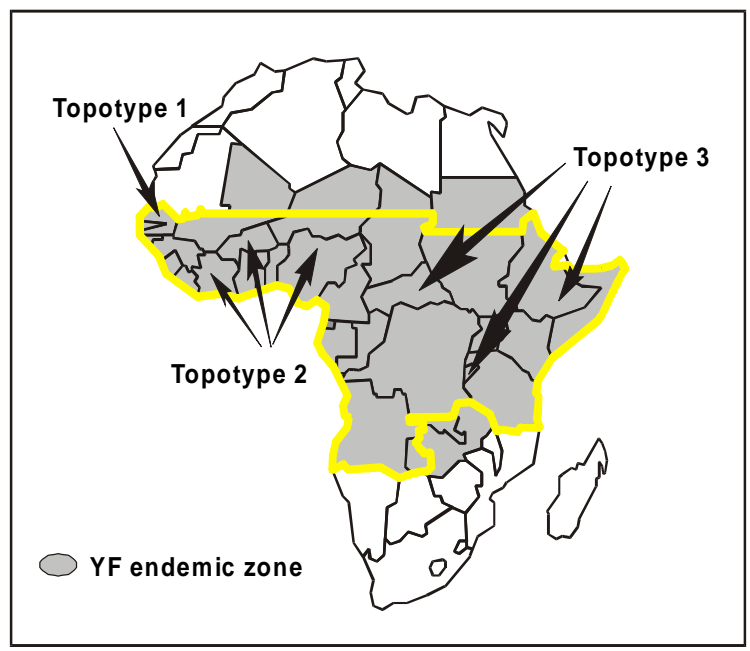

Figure 3. Distribution of yellow fever topotypes in Africa.
Using RNA oligonucleotide mapping, these genotypes have been segregated into three distinct non-overlapping regional topotypes or variants (22). The West African genotype consists of two variants, the Senegal-Gambia and the Cote d'Ivoire-Burkina Faso-Nigeria variants, while there is only one variant representing the Central Africa and East African genotype (22). The variants show considerable genetic stability over time, indicating that epidemics arise from local sources (23). One of the South American genotypes has not been recovered since 1974, suggesting that the virus may have been lost. All other South American strains fall into one major phylogenetic group, which in contrast to the African viruses, do not segregate into discrete geographical topotypes (21) (figure 3).

Yellow fever virus, a small ( 35 to $45 \mathrm{~nm}$ ) virus, possesses a single stranded positive polarity genome containing 10,862 nucleotides with a relative molecular mass of $3.75 \times 10^{6}$. It encodes for three structural proteins and up to 12 nonstructural proteins, which are synthesized in infected cells (24). The genome is surrounded by an envelope, which contains a single glycoprotein with type and group specific antigenic determinants. Yellow fever virus is inactivated by ether, chloroform, sodium deoxycholate, proteases, lipases, by heat $\left(56^{\circ} \mathrm{C}\right.$ for 30 minutes) and by ultraviolet light (25).

Yellow fever virus replicates in a wide variety of primary and continuous cell cultures (18). These include continuous monkey kidney (MA-104, Vero, LLC-MK2), baby hamster kidney (BHK), and porcine kidney cell lines as well as monolayers of primary chick and duck embryo fibroblast. Vaccine strains (17D and French neurotropic viruses) attain higher titters and produce more evident cytopathic effects (CPE), in these cultures. With wild strains, plaque formation is inconsistent and variable from strain to strain. Both 17D and parent Asibi virus grow in cell cultures of human origin, such as Chang liver cells, Henle embryonic intestine, HeLa and KB. Mosquito cell cultures are more sensitive that Vero cells or infant mice for primary isolation (18). While A. pseudoscutellaris (AP-61) cells consistently show CPE following infection with YF virus, infections of cloned $A$. aegypti and cells 
can be demonstrated by immunofluorescence and/or subpassage of mice or Vero cells (18). Intrathoracic inoculation of Toxorhinchites or $A$. aegypti mosquitoes is another isolation or assay method for YF virus. After a 10-16 day incubation period, inoculated mosquitoes can be examined directly by immunofluourescence or by subpassaging to a susceptible host, e.g., suckling mice (18). Yellow fever virus produces both neurotropic and viscerotropic patterns of infection in a variety of vertebrate hosts. Infant mice are highly susceptible to encephalitis following either intraperitoneal or intracerebral inoculation with YF virus (18). However, there is considerable variation between strains in their neuropathogenicity for mice. Older mice, as well as guinea pigs, are susceptible by intracerebral route. Monkeys intracerebrally inoculated with wild-type virus develop encephalitis, but die of viscerotropic yellow fever. In man and non-human primates (Rhesus cynomolgus macaques, viscerotropism is characteristic of YF virus infection by the peripheral route (18). As reported for other flaviviruses $(17,18)$, viral synthesis and maturation occurs predominantly in the rough endoplasmic reticulum of the host cell, while the site of formation of the envelope surrounding the virion remains unclear. Mature viral particles accumulate within the cisternae of membranous organelles and are released from the cell by exocytosis or by plasma membrane rupture. Hostcell macromolecular synthesis is not seriously affected by the YF infection (18). Treatment of cells with actinomycin D inhibits host cell RNA synthesis but does not affect viral RNA synthesis. Peak viral RNA synthesis occurs when the virus titre in the supernatant reaches a maximum. Three types of viral RNA are observed: the genome-size RNA with a sedimentation coefficient of $40 S$; the RNase-resistant RNA identified as the replicative intermediate, which is soluble in $2 \mathrm{~mol} / \mathrm{l} \mathrm{HCl}$ and sediments at about 20S; and the partially Rnaseresistant RNA, presumed to be the replicative form and sedimenting at about $28 \mathrm{~S}$ (18).

\section{The disease}

Yellow fever is an acute infectious disease characterized by a sudden onset with a two-phase development, separated by a short period of remission (17). The clinical spectrum of yellow fever varies from very mild, nonspecific, febrile illness to a fulminating, sometimes fatal disease with pathognomic features. Severe or classical YF, usually recognized during epidemics, begins abruptly, following an incubation period of 3-6 days or longer, after the bite of an infected mosquito. Fever $\left(39-40{ }^{\circ} \mathrm{C}\right)$, chills, intense headache, lumbosacral and generalized muscular pains, nausea and vomiting, conjuctival injection are the signs and symptoms associated with the first phase or period of infection (17). This syndrome lasts 3-5 days. The urine at this stage is dark in color and may not contain albumin. A slow pulse in relation to the fever (Faget's sign) is also typical at this stage. A period of remission lasting 12-24 hours, generally follows. This is characterized by a fall in temperature, disappearance of the headache, and an improvement in the general condition of the patient. The remission phase is followed by the intoxication period or hepatorenal phase, which is marked by a rise in temperature, the reappearance of generalized symptoms, more frequent vomiting, epigastric pain, and prostration (17). Jaundice appears at this stage. Bleeding diathesis, another common feature of this phase, is manifested by coffee grounds hematemesis (vómito negro), melena, metrorrhagia, petechiae, ecchymoses, and diffuse oozing from the mucous membranes. Dehydration results from vomiting and insensible losses. Renal dysfunction is marked by a sudden increase in albuminuria and diminishing urine output. Progressive tachycardia, shock and intractable hiccups are considered ominous and terminal signs. The case fatality rate of severe yellow fever is $50 \%$ or higher. Death usually occurs between the seventh and the tenth day after onset. Convalescence, with profound asthenia may last 1-2 weeks.

\section{Treatment}

In the absence of specific therapy, treatment of YF cases is chiefly supportive $(17,18)$. Since most YF cases occur in areas lacking basic hospital facilities, they do not benefit from availability of modern intensive care. In the early stages of the disease, therapy should focus on controlling the fever and vomiting, relieving the headache and abdominal pains, and managing the dehydration. 
During the stage of intoxication, suitable therapy based on careful patient monitoring should be administered to control the bleeding, and manifestations associated with hepatorenal damage. Appropriate treatment to control malaria and secondary bacterial infections should be administered where necessary $(17,18)$.

\section{Diagnosis}

It is clinically difficult to distinguish YF disease from many other tropical conditions, and often impossible when the condition is mild or atypical. The clinical symptoms associated with the early stages of YF infection are indistinguishable from those of malaria, and where the two diseases coexist, yellow fever should not be ruled out even in the absence of jaundice or the finding of malaria parasites in a blood smear. Other diseases resembling anicteric YF include typhoid fever, rickettsial infections, other arboviral fevers, and influenza. Yellow fever must also be differentiated from other diseases with hepatorenal dysfunction and/or hemorrhagic manifestations such as viral hepatitis, viral hemorrhagic fevers (Lassa fever, Marburg and Ebola virus diseases, CrimeanCongo hemorrhagic fever, Rift Valley fever), leptospirosis, etc. $(17,18)$.

Laboratory diagnosis of YF requires special reagents and techniques as well as expertise in the interpretation of test results. Specific diagnosis depends on histopathologic studies, isolation of the virus, demonstration of viral antigen or a specific antibody response $(17,18)$. For histopathology, liver samples may be obtained from fatal cases by abdominal incision or by the use of viscerotome or a large caliber biopsy needle. Liver samples obtained from a patient dying before the tenth or twelfth day after onset, is also suitable for virus isolation. Specimens should be divided into separate portions for virus isolation and for fixation and histopathology. Specimens for histopathology should be fixed in either Boiun's solution or $10 \%$ formalin. An examination of a paraffin section of a typical case of YF reveals an eosinophilic degeneration of the hepatocytes leading to the formation of Councilman's bodies, prominent midzonal necrosis and microvacuolar steatosis. However, histopathology of other infections, such as Lassa fever, Marburg and Ebola virus diseases, Crimean-Congo hemorrhagic fever, viral hepatitis, and leptospirosis, may be easily confused with that of YF. The virus is most readily isolated from acute stage serum obtained during the first 4 days of illness, but may be recovered from serum up to the 14th. day and, as earlier indicated, from the liver tissue at death. Several methods are available for the isolation of yellow fever virus from clinical specimens. These include, inoculation of suckling mice, the intrathoracic inoculation of mosquitoes, or the inoculation of cell cultures. Isolated virus can be identified using a variety of serological tests. An antigen-capture ELISA, which is as sensitive as virus isolation in suckling mouse, is available for rapid detection of virus in serum, blood or liver (18).

For serological diagnosis of YF infection, the following methods are useful: hemagglutination inhibition ( $\mathrm{HI})$, complement fixation (CF), and neutralization $(\mathrm{N})$ tests, single radial hemolysis, ELISA, IFA and RIA (17). The HI, IFA, and N antibodies appear within a week of onset; CF antibodies appear later. The plaque reduction neutralization test has replaced the less sensitive mouse neutralization test. Paired acute and convalescent phase sera are required to confirm diagnosis by demonstrating significant (usually a fourfold) rise in antibody titer. Determination of IgM antibodies either by the indirect IFA or ELISA, may indicate recent infection. The duration of IgM antibodies appears to be quite variable. A presumptive diagnosis of recent YF infection may be made when IgM antibodies are detected by ELISA or IFA or when there is a high specific CF antibody titer in a single sample taken during convalescence. Although IgM antibodies show relative specificity, prior exposures to other flaviviruses may sometimes complicate interpretation of results. In persons without prior flavivirus exposure, yellow fever 17D vaccine induces a neutralizing antibody, seroconversion and low titer (1:10-1:40) $\mathrm{HI}$ antibodies, but no detectable IFA or CF. However, persons with preexisting flavivirus antibodies respond to $17 \mathrm{D}$ vaccination with marked rises in yellow fever and heterologous $\mathrm{HI}$ and CF antibodies $(17,18)$. 


\section{The ecology of yellow fever}

Virus transmission occurs between man, mosquitoes and monkeys $(2,18)$. The mosquito vector, which may belong to one of several species, becomes infected by feeding on a viremic host (man or monkey) and then transmits the virus to another susceptible man or monkey. Although monkeys and man have been considered as the reservoirs of yellow fever, the true reservoir is the susceptible mosquito species that not only remains infected throughout life, but can also transmit the virus transovarially to a proportion of the descendants through infected eggs. Men and monkeys, on the other hand, play the role of temporary amplifiers of the amount of virus available for mosquito infection. In man highlevel viremia, required for mosquito infection, lasts from just before onset of infection until about the fourth day after onset, when specific antibodies begin to appear. Most African monkey species develop an effective viremia lasting several days or more, and produce protective antibodies after the viremia. Unlike some of the American species, African monkeys rarely die from yellow fever infection. American howler monkeys (Alouatta $\mathrm{sp}$.), spider monkey (Ateles sp.), squirrel monkeys (Saimirisp.) and owl monkeys (Aotus sp.) develop high levels of viremia and commonly die from yellow fever infection (17). On the other hand, capuchin monkeys (Cebus sp.), and wooly monkeys (Lagothrix sp.) develop subclinical yellow fever infections with viremia. The role of other nonhuman vertebrates in yellow fever transmission, such as African bush baby (Galago)

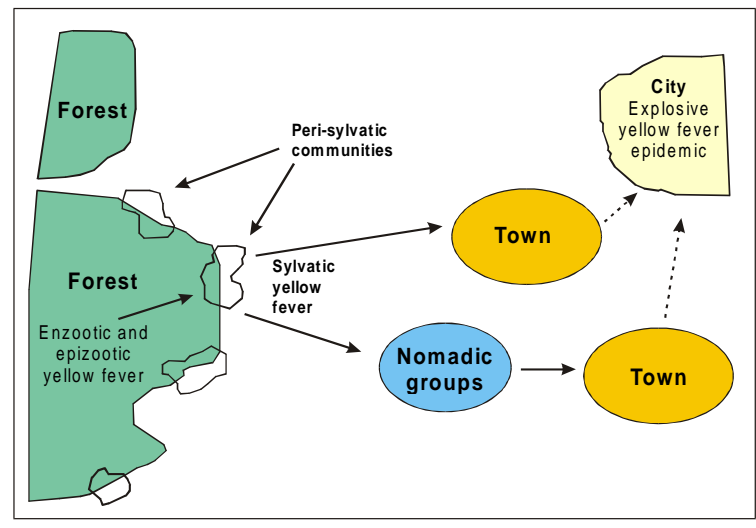

Figure 4. Yellow fever virus transmission cycles. and South American edentates, marsupials and rodents, remain undefined and require further studies (18).

\section{Epidemiology of yellow fever}

In the Americas, two types of epidemiological cycles are in operation: the jungle and the urban (17). Urban type yellow fever epidemic is transmitted from man to man by $A$. aegypti mosquitoes, while the jungle type is transmitted by the bite of a yellow fever infected Haemagogus or other forest-breeding mosquitoes. Virus activity is low with sporadic cases and focal outbreaks.

In Africa, three different epidemiological patterns, leading to the same clinical picture, are recognized for yellow fever virus transmission (17). These are the sylvatic or forest cycle, the $A$. aegypti-mediated urban cycle and an intermediate cycle bridging the sylvatic and urban cycles (figure 4). Transmission is determined by the complexity of the vegetational zones, rainfall patterns, abundance and distribution of vertebrate hosts and mosquito vectors. In the equatorial rain forest which extends from Guinea in the west to Uganda in the east and as far south as northern Angola, there is year round transmission of yellow fever between monkeys and $A$. africanus mosquitoes, in a manner analogous to jungle yellow fever in South America. Transmission is predominantly monkey to monkey, with sporadic human infection $(17,23)$. The humid and semihumid savanna extend from the African rain forest. However, during the rainy season, with resulting high population densities of hosts and sylvatic vectors ( $A$. furcifer, $A$. luteocephalus, $A$. vittatus), these areas of savanna forest mosaic and moist (Guinea) savanna experience repeated and sometimes high rates of yellow fever transmission (17). Periodic yellow fever epizootics occur in monkey populations with interhuman transmission. Virus survival and continuation of epizootics are ensured by vertical transmission in the mosquitoes. With most YF epidemics occurring in this vegetational zone, this is the major area of risk of transmission. This is also known as the intermediate zone of transmission (17). The dry savanna zone is characterized by very low rainfall and a short rainy season. Consequently, the sylvatic vector populations are 


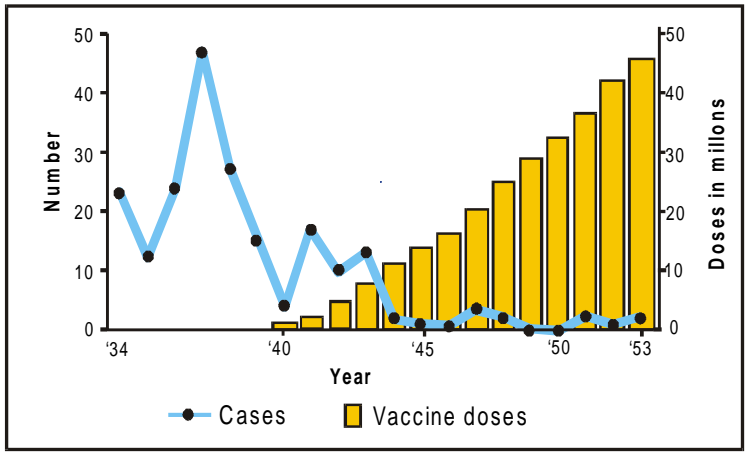

Figure 5. Control of yellow fever in Africa: the miracle of 1934-1953.

either too low or active for only a short period to sustain an epizootic. However, yellow fever infection can be introduced into the dry savanna zone and maintained in a cycle of interhuman transmission by the domestic vectors, $A$. aegypti mosquitoes, following the extension of an epizootic from the intermediate zone, or movement of infected persons into villages. Explosive urban $A$. aegyptiborne epidemics occur when the virus is introduced into urban centers or very dry savanna regions where water is stored in and around homes, and human population lives in association with domestic $A$. aegypti (17). Under such conditions, the epidemic can spread to distant places and from village to village along the lines of human communication. The extent and speed of virus spread is only limited by the distance an infected person or infected mosquito can move by available means of transportation.

\section{Prevention and control}

Two live attenuated vaccines have been used for the prevention or control of yellow fever epidemics (26). A yellow fever vaccine, the French Neurotropic Vaccine (FNV) was developed in 1930 , and consisted of desiccated brain of mice inoculated with the French neurotropic strain of yellow fever virus (27). Between 1939 and 1953, over 80 million vaccinations were performed by scarification, resulting in the virtual disappearance of yellow fever from French speaking countries of Africa (28). However, severe post-vaccinal reactions were developed by vaccinees (18), including systemic symptoms in approximately
$20 \%$, meningeal signs in 3-4\%, and post-vaccinal encephalitis in $0.5-1.3 \%$. An attempt to control the 1965 yellow fever outbreak in Senegal, using the neurotropic vaccine resulted in the identification of 248 cases of encephalitis with a $22 \%$ case-fatality rate (23). The manufacture of the French neurotropic vaccine was discontinued in 1980 (26). The second vaccine, the 17D vaccine, is a safe and efficacious live attenuated vaccine prepared from infected chicken embryo (12). About $95 \%$ of vaccinees develop measurable antibody within 10 days of primary vaccination. For international certification, immunization is valid for 10 years, but immunity may be lifelong, as antibodies have been shown to persist for as long as 30-35 years (18). Adverse reactions to the 17D vaccine include mild headache, myalgia or other mild symptoms in $2-5 \%$ of persons receiving the vaccine. Allergic reactions, including skin rash, urticaria and asthma occur in at a very low rate, less than one in a million, predominantly in persons with a history of allergy to eggs. No liver function test abnormalities are associated with 17D vaccination. The risks of encephalitis associated with the use of the 17D vaccine are minimal and it is the only vaccine currently produced $(18,26)$. Promotion of effective immunization strategies, both routine and supplemental, are required for the control YF in endemic countries (16). The four strategies proposed for the prevention and control yellow fever are: 1) routine immunization, 2) surveillance, (including vector monitoring and control), 3) outbreak prevention, and 4) outbreak response (29). All at-risk countries require a continuing and sensitive surveillance system for the early detection of YF cases, as a prerequisite for institution of rapid response to contain a potential outbreak. Laboratories with capability for differential diagnosis are essential because of the difficulties in distinguishing YF from other diseases with similar symptoms such as hepatitis, malaria, typhoid fever and other febrile jaundice. Other preventive measures include vector monitoring and control (29). A vigorous but well coordinated and continuous programme of eliminating the breeding sites (tires, artificial containers, etc.) of domestic vectors of yellow fever ( $A$. aegypti mosquitoes), treatment of potable water with temephos (Abate $\left.{ }^{\circledR}\right)$, perifocal spraying with 
organophosphorus iinsecticides, are effective steps in interrupting virus transmission (29).

\section{Impact of yellow fever on development through the ages}

At different stages of human development, yellow fever has caused untold hardship, and indescribable misery among different populations in America, Europe and Africa. Hundreds of thousands of people were affected by the disease through the ages, of which tens of thousands died. Yellow fever brought economic disaster in its wake, constituting a stumbling block to development. Along the trade routes between the settlements in North America and the West Indies, yellow fever was brought to New York in 1668 riding on the wings of $A$. aegypti mosquitoes breeding in water casks of old wooden trading ships. The 1668 outbreak was described as "particularly destructive in the cities of New York and Philadelphia" (2). Between 1668 and 1905, from as far north as Boston to New Orleans and the Mississippi valley, YF returned each succeeding summer, "decimating populations, paralyzing industry and trade, and holding the peoples of these regions in a state of perpetual dread of the Yellow Jack" $(1,2)$. Between 1668 and 1870, New York suffered no less than 15 epidemics. Thirty epidemics were reported in Philadelphia between 1668 and 1867 , with the most devastating epidemic being the 1793 outbreak. The epidemic started "soon after the arrival of refugees from Santo Domingo in August, and lasted for 7 weeks"(2). About 4,000 people died as a result of the epidemic. When yellow fever invaded the plains of the US in 1846, "the Mormons (during their march from Nanvoo to Utah) suffered from remittent and yellow fevers. Their track across the desert was marked by the graves of those who perished" (30-32). The most devastating of the eighteen yellow fever epidemics reported in New Orleans, between 1811 and 1878, occurred in 1853 with close to 5,000 cases and 1,000 deaths. The city of Charleston, South Carolina, lost 682 persons to yellow fever during the 1854 epidemic, and suffered at least 15 other major epidemics between 1690 and 1876. In the Mississippi Valley, the YF epidemic of 1878 caused the death of thirteen thousand people, and "by bringing business to a standstill resulted in an economic loss of more than one hundred million dollars" (2). The work of Reed and associates of the Rockefeller Commission (2) pointed clearly to mosquito eradication as the practical method of exterminating yellow fever. This principle was accepted and put to test with dramatic results by the government of Cuba. In February 1901, anti- mosquito measures to rid the city of domestic $A$. aegypti were started and by September of the same year, yellow fever was completely eradicated. This success was repeated in Panama, El Salvador, Nicaragua, Honduras, Guatemala, Ecuador, México, Perú, Colombia and Brazil. By the end of 1924, urban yellow fever had been eradicated in many locations of Central and South America (2). Although yellow fever has not been reported in North America since the $1905 \mathrm{New}$ Orleans outbreak, much of southern eastern United States has been reinfested with $A$. aegypti mosquitoes, increasing the possibility for a yellow fever outbreak (23).

\section{Central and South America}

Countries of Central and South America were not spared from the devastations of yellow fever (2,30-33). Between 1649 and 1900, over one hundred epidemics were reported in different countries in the region. The earliest reported YF outbreak occurred in 1649 in the West Indies (2). The most severe epidemic reported from the West Indies was the 1795 outbreak among European troops stationed in the West Indies. Approximately 31,000 people died during this epidemic. Other notable epidemics were the French Guiana epidemic of 1762 which raged for three years, the San Juan outbreak of 1804 , with mortality described as "inordinate" (34) and the Rio de Janeiro epidemic of 1804 , in which mortality was in excess of $95 \%$ (35). Colombia and Venezuela $(30,31)$ suffered frequent outbreaks between 1907 and 1929. In 1949, ten countries, most devastated by yellow fever (Brazil, Bolivia, British Guyana, Colombia, Ecuador, French Guyana, Panamá, Perú, Surinam and Venezuela) launched a vigorous eradication campaign against $A$. aegypti. By 1965 , urban breeding grounds of the mosquitoes had been destroyed 
and yellow fever disease eradicated from most urban centers in America (33). However, from 1985 to 1994, sylvatic yellow fever cases were reported in Bolivia, Brazil, Colombia, Ecuador, and Perú. During the decade, a mean of 154 sylvatic yellow fever cases were reported annually (range, 88-237 cases) from South America (23). In 1995, Perú reported a jungle-type yellow fever outbreak, with 440 cases and a case fatality rate of $38 \%$. This was the largest outbreak in South America since the 1950s. Urban yellow fever has not been reported in the Americas since 1954. However, $A$. aegypti mosquitoes have reinfested many tropical cities of South America, providing the potential for explosive urban outbreaks of yellow fever. Dengue fever, another arbovirus transmitted by $A$. aegypti, has made a dramatic comeback in the Americas with over 200,000 cases reported from 27 countries in South, Central America and the Carribean as of November 1995 (3).

\section{Europe}

Yellow fever, one of the most dreaded diseases during the seventeenth century slave trade on the Atlantic sea routes, inspired the legend of the Flying Dutchman. This was a vessel fated to haunt the Cape of Good Hope, because yellow fever broke out on the vessel, and no port allowed her to dock, and all the crew perished (33). Between 1649 and 1878, twenty-two outbreaks of yellow fever were reported from Gibraltar to Dublin, in Europe (33). Yellow fever was brought in ships to and from Africa and the West Indies, to Gibraltar in 1649 . The 1723 outbreak, probably the first episode of the disease in the heart of Europe, was reported in Lisbon, and eventually spread to London (33). But by far the greatest epidemic in Europe began in September 1730, when 22,000 people died after the arrival of the flotilla of Pintado. The flotilla came in from Cartegena, where many of Pintado's men had died of "el vómito prieto" $(30,34)$. Commenting on the outbreak, Bascome was reported to have said "...it was probably this pestilence which during the seven years 1729-35, raged in Vienna, Pignrol Fossano, Nizza, Rivoli, Asti, Larti, Acqui, Basle, Silesia, Thrasburg (Lower Rhine), Trino, Fresneuse (Lower Seine), Vimeux (Seine et Oise), Orleans (Loiret), Plouvirers
(Loiret), Meaux, Villeneuve, St. George (Seine et Maine), Bohemia, Denmark, Sweden and Russia $(1,35)$. During the military operation of 1741 , over 8,000 people were reported to have died as a result of yellow fever infection in Málaga, Spain. For the next 60 years, there were few reports of yellow fever outbreaks in Europe. At the beginning of the 19th century, yellow fever reappeared in Spain and Portugal. In 1821, no less than 20,000 deaths were reportedly caused by yellow fever disease in Spain, of which 5,000 of the fatalities were in Barcelona alone $(1,35)$. The 1857 outbreak in Oporto and Lisbon, Portugal was described as "awesome in both scale and mortality", and was the last major epidemic in Europe. Other outbreaks of interest, include the 1826 Dublin outbreak, being the most remote location of yellow fever outbreak in Europe, the Gibraltar outbreak of 1828 , with over 5,000 cases and more than 1,000 deaths; the 1861 outbreak in Saint Nazaire, France, brought in by "Anne Marie", a small wooden sailing ship from Havana. Before docking in Saint-Nazaire, the ship had already suffered a case fatality of $22 \%$ due to yellow fever $(1,35)$.

\section{Africa}

As far back as 1494, diseases, similar in signs and symptoms to YF had been reported from islands (Canary, Cape Verde, etc.) off the coast of Africa, and sometimes in coastal countries such as Gambia, and Sierra Leone (1). Since the latter half of the 18th century, outbreaks of yellow fever have occurred at intervals in Africa, with the 1778 outbreak of yellow fever among British soldiers stationed in St. Louis, Senegal, being the first documented episode of the disease (17). The clinical report of this outbreak published in 1782, read like extracts from modern day fiction on emerging and exotic diseases: "... the vomiting continued... It became green, brown, and at last black, and was coagulated in small lumps. A continual diarrhea, with grippings, now took place, by which a great quantity of black and putrid faeces was evacuated. The skin became now full of petechiae" $(1,34)$. Serious investigation of the yellow fever disease commenced in 1925 when the Rockefeller Foundation established Yellow Fever Laboratories in Ghana and Nigeria (2). Before 
mass immunization campaigns began in Africa, typical urban YF outbreaks occurred in different centers in West Africa and the Sudan. In addition, YF occurred as sporadic cases of jungle YF mainly in the forested areas. While epidemiological data on these outbreaks are not available, there are reports of YF outbreaks involving thousands of cases and deaths in Nigeria (1925-1928), Ghana (1926-1927, 1937) and the Gambia (19341935)(17). Between 1940 and 1953, in francophone West Africa, over 40 million doses of FNV were administered during compulsory mass YF vaccination exercise (figure 2). Consequently, yellow fever virtually disappeared from these areas, but remained as an endemic disease with periodic epidemic outbreaks in other countries where an immunization programme was not in force (16). The decline in the number of reported cases of YF resulted in a loss of interest in the disease and a progressive neglect of surveillance and YF immunization programmes in the latter half of 1950s. Furthermore, the production and use of FNV was stopped with increasing reports of severe and fatal encephalitis in children under the age of 12 years who had received the vaccine (25). Within five years of the cessation of mass $Y F$ vaccination campaigns, more countries in Africa began to experience outbreaks of YF. Between 1958 and 1962, Zaire (now the Democratic Republic of Congo), Sudan and Ethiopia reported severe outbreaks of YF. It was estimated that, during the Ethiopian yellow fever epidemic of 1960-62, there were 100,000 cases and 30,000 deaths (17). From 1969 to 1995 , epidemics of YF raged in varying proportions in different parts of Africa. The period 1988 to 1990 was an extraordinarily active period for YF. The worldwide total of 8,685 cases and 2,643 deaths for the three years, while gross underestimates of actual situation, still represented the greatest number of YF cases and deaths reported to WHO since 1948. African countries reported over $90 \%$ of the number of yellow fever cases and deaths, during this period. In 1992, YF appeared farther east in Kenya, a country that had been free of $Y F$ for more than 50 years. Improved laboratory based surveillance in Kenya detected yellow fever cases in 1994 and 1995. In 1996, five African countries, Benin, Burkina Faso, Ghana, Liberia and Nigeria reported a total of 1,132 yellow fever cases. Recent YF epidemics in Africa have primarily affected children younger than 15 years of age $(15,16)$, because many African countries abandoned routine mass $Y F$ vaccination campaigns since the 1960s, and opted for post outbreak emergency campaigns (26). Children accounted for $62 \%$ of 4,661 YF cases reported in Africa between 1965 and 1991. In Senegal, Burkina Faso and Cameroon, over $80 \%$ of YF cases occurred in children. For the first six years of the 1990s, Africa has reported 9.876 cases of yellow fever, which is over $70 \%$ of the total number of cases reported for the entire decade of the 1980s.

African countries at risk for yellow fever have traditionally used the "fire fighting" vaccination approach in combating recent YF outbreaks, often with disastrous effects. Apart from the great numbers of preventable deaths, this approach has resulted in the disruption of fragile health care delivery systems, enormous wastage of vaccines and has put a great strain on donor and existing national human and material resources. For example, Nigeria suffered a devastating epidemic of YF from 1986-1991 and imported over 30 million doses of YF vaccine to contain the epidemic. The country was unable to rapidly and effectively contain the epidemics because of her capacity and capability to effectively utilize the imported doses of YF vaccines were overwhelmed, leading to a wastage of over $30 \%$ of the imported vaccines, health services were diverted to cope with the massive epidemics, and vaccination exercise always lagged behind the outbreaks by at least three to four months. Consequently, the importation of massive doses of YF vaccine had little effect on an epidemic that raged unabated for more than four years and from one part of the country to the other. Enormous resources required to conduct emergency immunization campaigns have been mobilized following reports of YF epidemics in Nigeria, Liberia, Benin and other countries without routine YF immunization programme. It is estimated that attempting to control YF epidemics through emergency vaccination campaigns, at least seven times as costly as introducing YF vaccine in childhood immunizations (36). The true burden of yellow fever disease, during epidemic 
and interepidemic periods, has not been accurately determined, due to the insensitive disease surveillance systems in operation in $\mathrm{YF}$ endemic countries. Following the 1986 YF epidemic in Nigeria, two of the affected villages were abandoned, as the villagers moved out to settle in nearby villages, unaffected by the epidemic. Four years later, the villages remained desolate as the villagers refused to return. With the resurgence of the disease, especially in Africa, in the last two decades, yellow fever continues to decimate populations, and cause economic stagnation and underdevelopment. Perhaps the most disturbing aspect of recent yellow fever epidemics in Africa, is that it has affected predominantly children under the age of fifteen years $(15,16)$. The non-appreciation, by the government and health authorities, in YF endemic areas of the world, of the real impact of yellow fever on their development, is a modern day tragedy. It is an inexcusable tragedy, knowing that a safe and effective vaccine has been available for over 60 years, especially as the disease was once brought under control following mass vaccination exercises carried out between 1939 and 1953 in African countries under French colonial rule $(3,28)$.

\section{Yellow fever in Asia}

As early as 1934, concerns had been expressed about the possibility of yellow fever spreading across from east Africa to Asia (37). Despite the occurrence of yellow fever epidemics in 1940 in Sudan (37), from 1960-62 in Ethiopia (39), and from 1992-93 in Kenya $(40,41)$, Asia has remained free of the disease. Numerous reasons have been advanced for the failure of yellow fever to spread to Asia, including, 1) non introduction of yellow fever into Asia, 2) variation in human susceptibility to yellow fever, 3) variation in vector competence and/or behaviour, 4) flavivirus crossprotection, and 5) absence of maintenance cycle. None of these reasons has provided a satisfactory explanation for the failure of yellow fever to spread to Asia. However, while yellow fever has not yet spread to Asia, it could still occur. Therefore Asian countries should continue to maintain that all visitors from yellow fever endemic or at risk countries should have valid yellow fever vaccination certificate.

\section{Factors responsible for the resurgence of yellow fever disease}

Some of the factors responsible for the resurgence of yellow fever and indeed, other diseases, especially in Africa, include (42): collapse of health care delivery systems, poor or inadequate disease surveillance, inappropriate disease control measures, urban poverty with overcrowding and massive population movements, poor environmental management and indiscriminate deforestation.

Epidemics usually begin in rural areas, far removed from urban centers and the seat of national authorities responsible for taking control measures. Delays of two or more months are common between onset and recognition/reporting of epidemics.

Where an outbreak is promptly reported, confirmation of the clinical or presumptive diagnosis is generally impossible, because of the poor state of laboratory diagnostic facilities. Furthermore, when laboratory confirmation is available, responsible authorities are incapable of responding adequately and in a timely manner, with appropriate control measures. In many developing countries, health care delivery systems and infrastructures have suffered years of neglect resulting in shortages of basic equipment and supplies and low staff morale. Under this situation, health care institutions are unable to provide appropriate care for the sick. In the event of an epidemic, the community has sought alternative medical care with the possibility of increased risk of disease spread within the community where the sick are cared for by family members. Two approaches: mass vaccination campaigns and inclusion of yellow fever vaccinations in national EPI programmes, have been proposed for the control of yellow fever. Since the resurgence of yellow fever in Africa, only Gambia, among the African countries at risk for yellow fever (34), has successfully carried out a mass vaccination campaign, attaining a coverage of $95 \%$. Seventeen of the 34 have included yellow fever vaccination as part of the national EPI programme, with widely 
varying degree of success. One reason often adduced for the poor state of health in Africa is the state of underdevelopment arising from poverty or viceversa. Indeed poverty coupled with ignorance is responsible for the occurrence and severity of most infectious disease in Africa. Poverty in Africa manifests in different forms resulting in massive population movements to already overcrowded urban centers where environmental sanitation standards are appalling. The search for food and means of livelihood, the shortage and competition for arable farmlands lead to invasion of virgin forests and the extension of YF infected zones through bad environmental management. The 1994 outbreak of YF in Gabon illustrates this point. The outbreak began as a jungle-type outbreak in a remote mining camp, and later spread rapidly to villages outside the forest, where a shift to urban type was indicated by the presence of $A$. aegypti mosquitoes (2). While there is poverty in the developing world, it needs to be emphasized that this is not often due to a lack of material and human resources, but more from misplaced and misdirected priorities. For example, between 1990-1995, defence and military expenditure in many of the developing countries was between 15 to 273 times more than the expenditure on health and education combined (43).

\section{Options for control of yellow fever}

What are the options available for control of yellow fever in developing countries? Recently, WHO launched an initiative to combat the dramatic resurgence of $\mathrm{YF}$ in Africa, and control $\mathrm{YF}$ by the year 2000. The initiative which is to be coordinated with national ministries of health, will integrate the partnership efforts of bilateral agencies, other United Nations bodies and non-governmental organizations (44). The two goals of the yellow fever control initiative are: 1 ) the introduction, by 1997 , of yellow fever vaccine into the childhood immunization programme in all the 34 countries at risk, and 2) the attainment, by the year 2000 , of at least $80 \%$ coverage with yellow fever vaccine in children under 5 years of age in all the 34 countries. Four strategies are proposed to achieve these objectives (29): immunization, improved disease surveillance, outbreak prevention, and outbreak response. The promotion of effective immunization strategies, both routine and supplemental, is required for the control YF in the 34 African countries at risk for YF epidemics. The joint WHO/UNICEF Technical Group on Immunization in Africa recommended, in 1988, that YF immunization be integrated into the immunization programmes in all 34 countries at risk for YF epidemics (29). National immunization programmes are to implement the necessary strategies to achieve and sustain in each district at least $80 \%$ coverage by one year of age for all scheduled childhood vaccines including yellow fever. However, financing YF vaccine has been the major obstacle to its procurement. Although 17 countries have adopted the policy, only 13 (Angola, Burkina Faso, Central African Republic, Chad, Cote d'Ivoire, Gabon, Gambia, Mali, Mauritania, Niger, Senegal, and Togo) were able to obtain funds and procure the vaccine. Immunization coverage has ranged between $87 \%$ in the Gambia to $1 \%$ in Nigeria, with only 2 countries achieving more than $50 \%$ YF vaccine coverage in infants in 1995 . The Gambian experience is an example of the success of this strategy. Following the 1978-79 YF epidemic in the Gambia, and the successful YF mass vaccination carried out in 1978/79, in which $95 \%$ of the population over 6 months received a dose, YF vaccination was added to the EPI Programme in Gambia. The vaccine was given at the time of the child's visit for measles vaccine. Gambia has since then maintained a coverage of over $80 \%$, without a reported case of YF. This is in the presence of reported YF cases in Senegal, a country which literarily envelopes the Gambia. In addition to the effective introduction and achievement of high YF immunization coverage in infants, YF can only be brought under control if a concurrent well coordinated mass immunization campaign is embarked upon over a period of 5-10 years. The duration of the campaign and the focus target group will depend on the epidemiology of YF in each of the at risk countries.

All at-risk countries require a continuing and sensitive surveillance system for the early detection of YF cases as a prerequisite for institution of rapid response to contain a potential 
outbreak. Laboratories with capability for differential diagnosis are essential because of the difficulties in distinguishing YF from other diseases with similar symptoms such as hepatitis, malaria, typhoid fever and other febrile jaundice. The WHO Africa Region is strengthening disease surveillance to encourage timely and complete reporting of priority diseases and monitoring of standard performance indicators. Since 1994, WHO in collaboration with other partners, has organized training courses on YF diagnosis and vaccine potency testing, for over 80 technicians and scientists from laboratories in 20 African countries. Trainees return to their laboratories with supplies and diagnostic reagents. To further enhance YF diagnosis, training/refresher courses are planned for pathologists in the region to improve diagnostic capabilities based on histopathology.

The prime goal of the new WHO YF control initiative is to rapidly expand vaccination coverage for YF in Africa by linking it with mass campaigns against polio and measles, while integrating YF vaccination into routine childhood immunization programmes. The success of mass $\mathrm{YF}$ immunization in west Africa in the 1940's and 1950's highlights the effectiveness of achieving high coverage of the population. YF antibodies acquired through natural infection or vaccination probably persists for life. Therefore country specific YF mass campaigns will be required in countries at risk. Since millions of doses of YF vaccine will be needed to achieve $80 \%$ or greater coverage of both urban and rural populations, vaccine manufacturing companies must be encouraged to increase production.

Measures to rapidly control YF epidemics are hampered by the late recognition and reporting of the disease. Countries are being assisted by WHO to carry out activities that will enhance appropriate responses to reported YF outbreaks. These activities include: collection and testing specimens, epidemic investigation to determine the scope of the outbreak, entomological investigation and vector control, and institution of measures to prevent spread of virus from patients to mosquitoes. Emergency vaccination of at risk populations is made possible through a stock of YF vaccine maintained by $\mathrm{WHO}$, and which can be made rapidly available for outbreak response.

\section{Conclusion}

Why is yellow fever still a significant public health problem in developing world, and especially, Africa? Why, despite what we know of the virus, the availability of a safe efficacious vaccine, the disease still remains uncontrolled? Why is the international community that is so ready to flood Africa with aid (vaccine and logistic support) during an epidemic so reticent when it comes to prevention of the disease through support for childhood immunization and other preventive activities? Why are governments in developing countries so unconcerned by the devastations caused by YF? If YF is to be controlled, answers must be found urgently to these questions. A report on the 1748 yellow fever outbreak that plagued Senegal and the Guinea coast of West Africa, said in part "... in several towns, among the negro population, the mortality was so great that there were no sufficient left to bury the dead" (3). One hundred and thirty five years later, in another part of Africa, the chief of a village decimated by yellow fever welcomed our investigating team with almost identical words, "... Had you come four weeks ago, the young and the able-bodied would have welcomed you at the gate of our village with traditional hospitality. They now lie unburied for four days or more, because only the old are around, and they are too weak in body and in spirit to bury their young and ... their future". The tragedy of yellow fever disease in the developing world and especially in Africa is non-appreciation of the deleterious impact of YF on the economic and social development of large mass of the population by governments and health officials. In most African countries, a criminal nonchalance about YF control is shown by the government and educated elite, who have gone on to protect their families and friends with available YF vaccine and neglected the teeming masses of unvaccinated rural dwellers and residents of periurban slums. The initiative for yellow fever control in developing countries lies to a large extent with national governments and the people of yellow fever endemic countries. The human and material resources required to control 
yellow fever exist in these countries just as yellow fever is endemic. The failure to control YF in developing countries is not a failure of public health, but it is the failure of improper application of public health strategies. To control yellow fever and minimize its impact not only on the developing countries, but also on the entire world, governments of yellow fever endemic countries must seize the initiative for yellow fever control, reorder their priorities and support disease surveillance and control activities through political commitment and increased funding. International partners also need to reorder their priorities in terms of the scope and mode of support provided for disease control. Only then can look forward with the hope and confidence expressed on yellow fever disease by Major Gorgas in 1902 (1).

\section{References}

1. Augustin G. History of yellow fever. New Orleans: Searcy and Pfaff Ltd.; 1909.

2. Strode GK, editor. Yellow fever. New York: McGraw Hill Book Company Inc.; 1951.

3. Robertson SE, Hull BP, Tomori O, Okwo B, LeDuc JW, Esteves K. Yellow fever: a decade of reemergence. JAMA 1996;276:1157-62.

4. Groot H. Abstracts. XV International Congress for Tropical Medicine and Malaria. Cartagena de Indias, Colombia, August 20-25, 2000. Cartagena: Universidad de los Andes, Instituto de Inmunología, Corporación para Investigaciones Biológicas, Sociedad Colombiana de Parasitología y Medicina Tropical; 2000. p.155-6.

5. Smith A. Yellow fever in Galveston, Republic of Texas, 1839. Austin, Texas: University of Texas Press; 1951.

6. Finlay $\mathbf{C J}$. Yellow fever: its transmission by means of the Culex mosquito. Am J Med Sci 1886;92:395.

7. Kelly HA. Walter Reed and yellow fever. New York: McClune, Phillips \& Co.; 1907.

8. Soper FL. Jungle yellow fever: new epidemiological entity in South America. Rev Hyg Saude Publica 1936; 10:107-44.

9. Haddow AJ, Gillette JD, Highton RB. Yellow fever. Bull Ent Res 1947;37:301.

10. Germain M, Cornet M, Mouchet J, et al. Recent advances in research regarding sylvatic yellow fever in West and Central Africa. Bull Inst Pasteur 1982; 80:31530 .

11. Theiler M, Smith HH. Use of yellow fever modified by an in vitro cultivation for human immunization. J Exp Med 1937;29:62-4.
12. Theiler $\mathbf{M}$. The development of vaccines against yellow fever - Les Prix Nobel de 1951. En: Collected papers by members of the staff. New York: Division of Medicine and Public Health of the Rockefeller Foundation; 1952.

13. Stokes A, Bauer JH, Hudson NP. Transmission of yellow fever to Macacus rhesus: preliminary note. JAMA 1928;90:253-4.

14. Stokes A, Bauer JH, Hudson NP. Experimental transmission of yellow fever to laboratory animals. Am J Trop Med 1928;8:103-64.

15. UNICEF/WHO. Joint Technical Group on Immunization for the African Region. Report of the Third Meeting, Nairobi; 1988.

16. Tomori O, Nasidi A, Mung K. Status of yellow fever vaccination in the Expanded Programme on Immunization (EPI). En: Proceedings of the 4th. International Seminar on Immunization in Africa, Yamoussoukro, Cote d'Ivoire. Lyon: Foundation Marcel Merieux; 1994. p.107-12.

17. World Health Organization. Prevention and control of yellow fever in Africa. Geneva: WHO; 1986.

18. Monath TP, Heinz FX. Flaviviruses. En: Fields BN, Knipes DM, Howley PM, Chanock RM, Melnick JL, Monath JL, Roizman B, Straus SE, editors. Field's Virology. Third edition. Philadelphia: Lippincott-Raven Publishers; 1995. p.961-1034.

19. Clarke DH. Antigenic analysis of certain group B arthropod-borne viruses by antibody absorption. J Exp Med 1960;111:21-32.

20. Fitzgeorge R, Bradish CJ. The in vivo differentiation of strains of yellow fever virus in mice. J Gen Virol 1980; 46:1-14.

21. Chang GJ, Cropp CB, Kinney RM, Trent DW,Gubler DJ. Nucleotide sequence variation of the envelope protein gene identifies two distinct genotypes of yellow fever virus. J Virol 1995;69:5773-80.

22. Deubel V, Digoutte JP, Monath TP, Girard M. Genetic heterogenecity of yellow fever virus strains from Africa and the Americas. J Gen Virol 1986;67: 209-13.

23. Monath TP. (1991) Yellow fever: Victor, Victoria? Conqueror, Conquest? Epidemics and research in the last forty years and prospects for the future. Am J Trop Med Hyg 1991;45:1-43.

24. Rice CM, Lenches EM, Eddy SR, Shin SJ, Sheets RL, Strauss JH. Nucleotide sequence of yellow fever virus: implication for flavivirus gene expression and evolution. Science 1985;229:726-35.

25. Monath TP. Yellow fever. En: Warren KS, Mahmoud AAF, editors.Tropical and geographical medicine. Second edition. New York: Mc Graw Hill Inc.; 1990. p.66174.

26. Robertson SE. Yellow fever: the immunological basis for immunization. Geneva: World Health Organization; 1993. 
27. Durieux C. Preparation of yellow fever vaccine at the Institut Pasteur, Dakar. En: Smithburn KC, Durieux C, Koerber MD, Penna GWA, Courtois D, editors. Yellow fever vaccination. Geneva: WHO; 1956. p.31-2.

28. Durieux C. Mass yellow fever vaccination in French Africa south of the Sahara. En: Smithburn KC, Durieux C, Koerber MD, Penna GWA, Courtois D, editors. Yellow fever vaccination. Geneva: WHO; 1956. p.115-21.

29. WHO Global Programme for Vaccines and Division of Emerging and other Communicable Diseases. A framework for control of yellow fever in Africa. Geneva: WHO; 1956.

30. Hobson W. World health and history. Bristol: Wright; 1963.

31. Carter HR. Yellow fever: an epidemiological and historical study of its place of origin. Baltimore: Williams and Wilkins Co.; 1931.

32. Busvine JR. Disease transmission by insects: its discovery and ninety years of efforts to prevent it. New York: Springer-Verlag; 1993.

33. Maurice J. Yellow fever makes comeback. Soumen Laakarilehti 1993;48:3057-61.

34. Scott HH. A history of tropical medicine. London: Edward Arnold and Co.; 1942.

35. Vainio J, Cutts F. Yellow fever: working document for yellow fever technical concensus meeting, EMC/GPV/ EPI. Geneva: WHO; 1998.
36. Monath TP, Nasidi A. Should yellow fever vaccine be included in the Expanded Program of Immunization in Africa? A cost-effectiveness analysis for Nigeria. Am J Trop Med Hyg 1993;48:274-99.

37. Duddley SF. Can yellow fever spread into Asia? An essay on the ecology of mosquito-borne disease. J Trop Med Hyg 1934;37:273-8.

38. Mahaffy AF, Hughes TP, Smithburn KC,Kirk R. Isolation of yellow fever virus in Anglo-Egyptian Sudan. Ann Trop Med Parasitol 1941;35:141-8.

39.World Health Organization. Annual epidemiological and vital statistics. Geneva: WHO; 1964.

40. World Health Organization. Yellow fever. Wkly Epidemiol Rec 1995;70:175-6.

41. World Health Organization. Yellow fever. Wkly Epidemiol Rec 1996;71:103.

42. Tomori O. Factors in the reemergence of yellow fever in West Africa. En: Saluzzo JF, Dodet B, editors. Factors in the emergence of arbovirus diseases. Paris: Foundation Marcel Merieux; 1997. p.167-73.

43. UNICEF. Progress of the Nations. New York: UNICEF; 1997.

44. World Health Organization. WHO appeals for action to combat dramatic resurgence of yellow fever in Africa. WHO Press Release 1996;67. 